\title{
Making the Numbers? "Short Termism" \& the Puzzle of Only Occasional Disaster
}

\section{Citation}

Rahmandad, Hazhir, Nelson P. Repenning, and Rebecca Henderson. "Making the Numbers? 'Short Termism' \& the Puzzle of Only Occasional Disaster." Harvard Business School Working Paper, No. 15-027, October 2014.

\section{Permanent link}

http://nrs.harvard.edu/urn-3:HUL.InstRepos:13350435

\section{Terms of Use}

This article was downloaded from Harvard University's DASH repository, and is made available under the terms and conditions applicable to Open Access Policy Articles, as set forth at http:// nrs.harvard.edu/urn-3:HUL.InstRepos:dash.current.terms-of-use\#OAP

\section{Share Your Story}

The Harvard community has made this article openly available.

Please share how this access benefits you. Submit a story.

Accessibility 


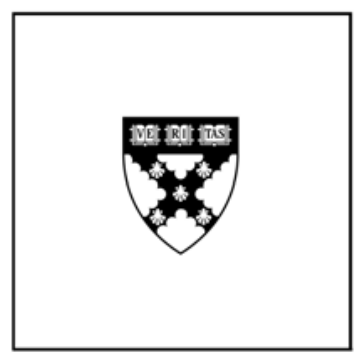

\title{
Making the Numbers? \\ "Short Termism" \& the Puzzle of Only Occasional Disaster
}

\author{
Hazhir Rahmandad \\ Nelson P Repenning \\ Rebecca Henderson
}

\section{Working Paper}

15-027

October 17, 2014 


\title{
MAKING THE NUMBERS?
}

\section{“SHORT TERMISM” \& THE PUZZLE OF ONLY OCCASIONAL DISASTER}

\author{
Hazhir Rahmandad \\ Visiting Associate Professor, MIT Sloan \\ Associate Professor of Industrial and Systems Engineering, Virginia Tech
}

\section{Nelson P Repenning}

School of Management Distinguished Professor of System Dynamics and Organizations Studies MIT

<nelson@mit.edu>

\section{Rebecca Henderson}

John and Natty McArthur University Professor, Harvard University and Faculty Research Fellow, NBER 


\begin{abstract}
Much recent work in strategy and popular discussion suggests that an excessive focus on "managing the numbers"--delivering quarterly earnings at the expense of longer term investments--makes it difficult for firms to make the investments necessary to build competitive advantage. "Short termism" has been blamed for everything from the decline of the US automobile industry to the low penetration of techniques such as TQM and continuous improvement. Yet a vigorous tradition in the accounting literature establishes that firms routinely sacrifice long-term investment to manage earnings and are rewarded for doing so. This paper presents a model that reconciles these apparently contradictory perspectives. We show that if the source of long-term advantage is modeled as a stock of capability that accumulates over time, a firm's proclivity to manage short-term earnings at the expense of long-term investment can have very different consequences depending on whether the firm's capability is close to a critical "tipping threshold". When the firm operates above this threshold, managing earnings smoothes revenue and cash flow with few long-term consequences. Below it, managing earnings can tip the firm into a vicious cycle of accelerating decline. Our results have important implications for understanding managerial incentives and the internal processes that create sustained advantage.
\end{abstract}


Everyone who has worked with American managements can testify that the need to satisfy the pension fund manager's quest for higher earnings next quarter, together with the panicky fear of the raider, constantly pushes top managements toward decisions they know to be costly, if not suicidal, mistakes. The damage is greatest where we can least afford it: in the fast-growing middle-sized high-tech or highengineering firm that needs to put every available penny into tomorrow. (Drucker 1986) (Quoted in (Laverty 1996))

\section{Introduction.}

There is little doubt that the desire for smooth, reliable earnings has a significant effect on managerial behavior. Even the most casual visit to a publicly-traded company during a period of lowerthan-expected revenue reveals the lengths to which managers will go to "meet their numbers", doing anything from banning travel and eliminating training to canceling investment projects and delaying maintenance. Indeed, research within the finance and accounting literatures finds that managers do sacrifice (at least some) long-term investments in response to pressure from the capital markets. Graham et al.'s, (2005) large-scale qualitative study of CFOs and CEOs finds that $78 \%$ of the managers surveyed admit to forgoing some long-term value in favor of smoother earnings. Healy and Wahlan (1999), in a summary of the literature suggest that earnings management is pervasive, while Brav et al. (2005) find that capital market pressures lead managers to "avoid cutting dividends at all costs" even if this means bypassing NPV positive investments and Bartov (1993) shows that managers routinely time asset sales to smooth inter-temporal earnings changes. Benner (2007; 2010) has further suggested that firms going through significant technological transitions face particularly intense pressure from analysts, causing them to reduce capital investment and investment in $R \& D$. But does such a focus on short-term results actually detract from overall firm performance? Despite the ubiquity of this practice, both popular opinion and the available data remain decidedly mixed and the strategy literature takes a distinctly different perspective from that which dominates the finance and accounting literatures.

Research in strategy has long stressed the importance of sustained investment over long periods of time as a key source of competitive advantage. Scholars working within this tradition have suggested that the unique resources and distinctive organizational competences that underlie enduring supra-normal 
returns cannot be developed instantaneously but must be "grown" gradually over time (Dierickx and Cool 1989). For example, Wal-Mart's superior IT capabilities were built through sustained investment over many years; by the time K-Mart attempted to respond by building equivalent skills the investment required was more than their balance sheet could sustain. Similarly the organizational competencies developed by firms such as Nordstrom, Southwest, Toyota, McKinsey and Merck appear to rest on the slow accumulation of mutual trust and local or "sticky" knowledge that takes years to develop (Helfat 2007; Gibbons and Henderson 2010).

This understanding has led to the suggestion that the short term orientation of American capital markets and American managers is a significant problem. Commenting on the recent meltdown of the US financial system, William Donaldson, a former head of the securities and exchange commission, said "The excessive focus by too many corporations on achieving short-term results... certainly is one of the root causes for some of the problems we face today (Rummel 2008).” Donaldson is not alone in his views: both academics and pundits are fond of highlighting the "tyranny of quarterly earnings" as the principal reason for the perceived decline of the western economy (Laverty 1996; The Aspen Institute 2009; Haldane 2010; Dallas 2011).

Consistent with this view, there are plenty of examples of once successful companies whose efforts to achieve short-term performance targets appear to have had a negative impact on their willingness to make important longer term investments. GM's recent recall challenges are thought to stem from short-sighted decisions and, more generally, the ongoing woes of the US auto industry are often attributed to their unwillingness to address the eventual need for smaller fuel-efficient vehicles in favor of continuing to sell profitable trucks and sport utility vehicles (e.g., Ingrassia 2010). Similarly, Pfeffer and Sutton (2000: 142-147) document how a focus on short-term results severely weakened Hewlett-Packard's much vaunted employee focused culture, while the explosion at BP's Texas City plant that killed 15 people was blamed on BP's short term orientation (Baker, Bowman et al. 2007). At a more micro level, a sequence of papers exploring the dynamics of process-focused improvement suggests that 
many firms are reluctant to invest in practices that raise profitability in the long term if they come at the expense of short term performance (Easton and Jarrell 1998; Repenning and Sterman 2001; Repenning and Sterman 2002). Work in the innovation tradition suggests that one of the reasons firms experience difficulty in responding to discontinuous technological change is that they are reluctant to make investments in the next generation technologies at the expense of investment in the status quo (Christensen 1997). Similarly, work in organizational economics suggests that a focus on short-term measureable performance can induce managers to neglect those tasks for which clear performance measures are not available (Holmstrom and Milgrom 1991), and that rewarding short-term performance when managerial ability is unclear can lead managers to "borrow" earnings from the future at an unfavorable rate (Stein 1989).

In contrast to this collection of case evidence and theory most large sample studies in the accounting literature suggest that "managing earnings" and "meeting analyst expectations" are systematically associated with superior performance. While Bhojraj et al. (2009) find that firms that manage to marginally beat earnings forecast through manipulation improve their stock price in the short term but have lower ROA over time, Barth et al. (1999) find that firms that report continuous growth in annual earnings earn a premium in the market. Similarly, Bartov et al. (2002) find that firms that meet or beat analyst expectations often report superior operating profits and Gunny (2010) finds that taking "real" actions such as reducing R\&D or reducing SG\&A to increase income has a positive effect on subsequent ROA.

A significant body of theory explains these results by suggesting that they reflect agency or information problems. Managers who "make their numbers" may be signaling both that they know what they are doing and that the firm's performance is under control. For example, Bowen et al. (1995) and Burgstahler and Dicheu (1997) suggest that those who "manage earnings" enhance their reputation with key stakeholders and thus obtain better terms of trade while Farrell and Whichbee (2003) suggest that 
"making the numbers" reflects career concerns on the part of senior managers who would otherwise lose their jobs.

The idea that sacrificing some long-term investment for the sake of short-term earnings management might not be entirely disastrous is further supported by the observation that, to paraphrase Mark Twain, reports of the demise of the western economy have often been greatly exaggerated. A former SEC chief, Harold Williams, said, in an address given in November 1980 (Williams 1980), "I believe that the most fundamental problem facing us is that we have lost our sense of the future-we tend increasingly to focus on the short-run and to ignore the longer-range consequences of business and political decisions." Williams' remarks failed to predict what would eventually become the longest peacetime expansion in US economic history, and there is little reason to believe that managers became less shortsighted during the period. Similarly while there is general agreement that the managers of publicly traded companies in Germany and Japan face significantly less pressure from their investors for short term performance, there is no systematic evidence that they outperform their UK or US listed rivals or that the German or Japanese economies are any more innovative than those of the US (Peek and Rosengren 2005; Dustmann, Fitzenberger et al. 2014).

How are we to make sense of this apparent paradox? When does a short term, target-driven focus increase performance and when does it lead to the erosion of critical long-term capabilities and a failure to invest in new markets and new technologies? In this paper we attempt to answer this question through the development of a simple model that captures the dynamics associated with managing earnings. Our formulation builds on a premise central to the strategy literature: long-term investment leads to the development of a stock of "capability" which continually erodes through natural entropy and thus requires continued investment and maintenance. We think of capability as including many competitively significant assets - particularly organizational capabilities, but also such intangibles as reputation and brand value. Critically, the stock of capability and its effect on performance can neither be easily measured nor predicted by the firm. Investments in capability are thus likely to be driven more by rules of 
thumb and managerial intuition than by precise calculation. We then define firm performance as a function of the effort devoted to short-term performance and the current level of capability, thus presenting the firm with the task of trading off investments in long-term capability against short-term revenue generation. We use the model to study the dynamics that emerge when firms try to "manage earnings" by changing the emphasis placed on short-run revenue performance in response to exogenous shocks to revenue.

Analyzing our model yields several insights. First, we show that conceptualizing capability as a stock or level variable implies that the firm faces a temporal trade-off in making resource allocation decisions. If managerial time is scarce, increasing the attention dedicated to capabilities necessarily results in a temporary decline in overall performance - a pattern of "worse before better". Conversely, reducing the time dedicated to cultivating capabilities leads to a temporary increase in performance - a pattern of "better before worse." Second, combining these physical dynamics with the efforts of managers to smooth earnings yields a system characterized by two stable equilibria separated by a tipping threshold. Critically, this structure implies that attempts to manage earnings can produce very different outcomes depending on their intensity. As long as the resource adjustments targeted at smoothing performance keep the system above its tipping threshold, they will have a only a second-order effect on the long-run average performance while significantly reducing its variation around the mean. Above the tipping threshold managing earnings thus offers several positive benefits including improved internal financial discipline and higher external investor confidence. Since it seems plausible that this is the prevailing state most of the time in most industries, our analysis suggests that it is not surprising that the accounting literature finds that most firms smooth earnings and are rewarded by the market for doing so. However, if, in an effort to maintain earnings stability, capability is allowed to fall below this critical threshold, then efforts to smooth earnings become a path to failure. The firm enters a vicious spiral created by an increased emphasis on revenue generation and declining organizational capability which, left unchecked, eventually leads to failure. 
Third, we use the model to identify the conditions under which firms are most prone to "tipping" into this pathological set of dynamics. We show that the risk of tipping into a vicious spiral of declining capability increases with the manager's willingness to shift investment in response to short term revenue shortfalls. Those managers who "overweight" short-term returns even when times are good are significantly more likely to tip towards disaster.

Finally, we explore the effects of increasing demand variability on these dynamics. We show that when demand is relatively smooth, firms that rapidly shift investment to keep day to day revenues stable minimize revenue variability and thus presumably maximize their equity performance with no significant long-term penalty. However as demand variability increases, or lasts for longer periods of time they become significantly more likely to tip into disaster than the firms that respond less dramatically to shortfalls in immediate revenue.

These results have several implications for our understanding of the sources of competitive advantage. Most critically, they suggest that whether earnings management is a source of improved performance or deeply pathological is a matter of degree, and that the dynamics of the system are such that it is relatively easy for managers to learn the wrong lessons about the optimal mix of the two activities. Unless one holds to heroic assumptions about managers' understanding of the system in which they are embedded, it appears that managers cannot necessarily be counted on to make this trade-off in the best interests of the firm over the long-term. Our results thus suggest that organizational practices that protect investments in capability from the inevitable desire to cut them during down periods are likely to be a key source of persistent above average firm performance. Most notably, compensation systems that rely on relational contracts and subjective performance measures to reward the long term development of capability may prove to be a key contributor to sustained above-average performance.

We organize our arguments as follows. In the next section we present our model, first analyzing the implications of our conceptualization of capability and performance. Following that, we add a 
decision rule to the model in which managers treat earnings management as a simple control problem and then analyze its dynamics. Finally, we discuss the implications of our results for future research.

\subsection{The Model}

\subsection{Capability and Performance}

We begin the specification of our model with the notion of capability. Following Dierickx and Cool (1989) we hypothesize that because they cannot be acquired directly, capabilities are usefully conceptualized as being the outcome of a process of accumulation and therefore behave as stock or level variables. Managers in this formulation cannot influence the level of capability directly, but instead control only its rate of change. Thus, for example, managers cannot immediately transform a poorly maintained production line and a poorly trained workforce into a high performance operation. Instead, they must invest in maintenance, process improvement and training, and, with time, operational performance will improve. Conversely, if managers suddenly begin to neglect maintenance and training, operational performance does not immediately decline; time is required before poorly maintained equipment begins to break and the combination of turnover and forgetting yield a poorly skilled workforce.

Consistent with prior models of capability dynamics (Rahmandad 2012), we model capability, $C$, as a stock or level variable whose rate of change is determined by two factors, investment and erosion:

$$
\frac{d C}{d t}=e_{C} \rho-\frac{C}{\tau}
$$

Investment, the first term, is the product of the effort the firm dedicates to developing and maintaining capability, $e_{c}$, and the productivity of those efforts, $\rho$. Erosion is captured by the second term: absent investment, capability erodes with an average delay of $1 / \tau .{ }^{1}$ We specify the firm's revenue,

\footnotetext{
1. Note our formulation is simpler than the one proposed by Dierickx and Cool (1989) who suggest that managers may also influence the rate with which capability erodes. For simplicity, we assume that erosion happens autonomously and that managers influence capability solely through the investment term.
} 
$R$, as a constant return to scale Cobb-Douglas function of the firm's capability, $C$, the effort currently being dedicated to generating revenue, $e_{R}$, and an environmental shock, $S$ :

$$
R=C^{(1-\beta)} e_{R}^{\beta}(1+S)
$$

Finally, we assume that the resources available to the firm are bounded by $h$, the number of available hours of effort, and define $u$ as the fraction of that effort allocated to revenue generation.

$$
\begin{aligned}
& e_{R}=u h \\
& e_{C}=(1-u) h
\end{aligned}
$$

In the long run firms could in principle choose to increase $h$ but to focus attention on the impact of earning management we assume $h$ is fixed. Calculating the steady state optimal allocation fraction, $u^{*}$, which assumes a constant allocation fraction and steady-state capability level, is straightforward:

$$
u^{*}=\beta
$$

\subsection{Earnings Management and Capability Investment}

The evidence suggests considerable variation in how different firms trade-off mean performance and variability around that mean. To study how such differences in preferences might influence the system's dynamics, we use an investment allocation rule that allows us to easily vary the firm's focus across a continuum ranging from the short to the long run. On one side of that spectrum we imagine a firm that cares about meeting short-term revenue targets and uses the following decision rule:

$$
u_{S R}=\operatorname{Min}\left(1, u^{*}\left(\frac{R\left(u^{*}, 0, C^{*}\right)}{R\left(u^{*}, S, C\right)}\right)^{\gamma}\right)
$$

Our hypothesized managers begin with the steady-state optimal allocation, $u^{*}$, and then adjust that allocation to try to minimize the gap between the current revenue under $u^{*}, R\left(u^{*}, S, C\right)$, and the market's expectation. Markets likely do not observe current capabilities directly, so market expectation, $R\left(u^{*}, O, C^{*}\right)$, reflects a firm that is well managed, i.e. has a capability around the optimal $\left(C^{*}\right)$ level. Moreover, the market does not foresee environmental shocks or discounts them due to agency concerns (e.g., Stein 1989). The parameter $\gamma$ represents the intensity of the firm's effort to offset environmental 
shocks to maintain smooth earnings and varies between 0 and $1 / \beta$, with $\gamma=1 / \beta$ representing a situation in which the firm attempts to completely offset any revenue excess or shortfall by reallocating effort.

On the other end of the continuum, we imagine a firm that cares only about expected long term results and acts rationally. Solving the finite horizon dynamic program yields (approximately) the following decision rule for our long run (LR) firm (see appendix for details) ${ }^{2}$ :

$$
u_{L R}=\operatorname{Min}\left(1, u^{*}\left(\frac{C}{C *}\right)\right)
$$

The firm focused on the long run pays no attention to earnings, which are subject to environmental shocks, but instead always works to insure that capability, $\mathrm{C}$, is equal to its optimal level, $\mathrm{C}^{*}$. Combining both the short and long decision rules (6.1 and 6.2) into a single equation yields the following decision rule for $u$ :

$$
u=\operatorname{Min}\left(1, u^{*}\left(\frac{R\left(u^{*}, 0, C^{*}\right)}{R\left(u^{*}, S, C\right)}\right)^{\gamma}\left(\frac{C}{C^{*}}\right)^{1-\gamma \beta}\right)
$$

By adjusting $\gamma$ over $[0,1 / \beta]$, our formulation allows us to analyze a continuum of decision rules, ranging from an exclusive focus on meeting current expectations, $\gamma=1 / \beta$, to an exclusive focus on long run performance, $\gamma=0$. Our formulation thus allows us to study two competing forces that shape managerial action. The logic of a "rational" agent is captured with the capability term and the behavioral market pressures to produce smooth performance are incorporated by the revenue adjustment term. By changing $\gamma$ we can examine the outcomes generated by any combination of long run "rational" choice and shortterm focus.

The remainder of the model's specification follows the explanations above and is straightforward:

\footnotetext{
2 The solution to the finite horizon dynamic program includes a term for "end" effects (capturing the shift in allocation to benefit from exhausting capability's terminal value). To focus on the steady-state behavior (early in the finite horizon) of managers and for simplicity we do not include that term here. The infinite horizon solution (also discussed in the online appendix and briefly in the analysis) is very similar to equation 6.3, with an adjustment for discounting, which does not change the results qualitatively.
} 


$$
\begin{aligned}
& R\left(u^{*}, 0, C^{*}\right)=C^{*(1-\beta)} e_{R}^{* \beta} \\
& R\left(u^{*}, s, C\right)=C^{(1-\beta)} e_{R}^{* \beta}(1+S) \\
& e_{R}^{*}=u^{*} h \\
& C^{*}=\left(1-u^{*}\right) h \rho \tau
\end{aligned}
$$

\subsection{Model Overview}

These assumptions yield a system comprised of four key feedback loops (see figure 1). First, there is the balancing Capability Erosion loop; absent ongoing investment, capability erodes towards zero, with an average delay of $\tau$. Second, the decision rule described above results in two balancing loops Make the Numbers and Capability Preservation. As expected revenue, $R\left(u^{*}, S, C\right)$ falls below its target, $R\left(u^{*}, 0, C^{*}\right)$, managers concerned with short term results (i.e. those with non zero values of $\gamma$ ) increase the effort dedicated to revenue generation (due to term $\left(\frac{R\left(u^{*}, 0, C^{*}\right)}{R\left(u^{*}, S, C\right)}\right)^{\gamma}$ in 6.3), which, in the short run, increases revenue and closes the gap. Similarly, when capability deviates from its optimal value $\left(C^{*}\right)$, effort will be allocated towards investing in it (due to term $\left(\frac{C}{C^{*}}\right)^{1-\gamma \beta}$ in 6.3). Finally, a reinforcing loop may emerge as a result of the interaction between Make the Numbers ${ }^{3}$ and Capability Preservation loops. We call this the Capability Tipping loop. Replacing equations 7 and 8 into 6.3 we can see that the Capability Tipping loop is active only when $\gamma>1$, when a deviation in capability from the optimal value can lead to managerial reactions that further reinforce that deviation. For $\gamma<1$ the effect of Capability Preservation loop on capability levels is stronger than the Make the Numbers loop and thus any deviation from $C^{*}$ is balanced in effort allocation. Therefore $\gamma=1$ is a critical threshold in 6.3, below which the Capability Preservation mechanism dominates the dynamics and above which Capability Tipping becomes salient.

Notice that the Capability Tipping loop can act as either a virtuous or vicious cycle and will tend to amplify whichever behavior is currently in progress. For example, exceeding the revenue target allows

\footnotetext{
3 "Make the Numbers" loop requires at least one state variable. Our formulations assume this loop adjusts quickly relative to the dynamics of capability and thus the system can be reduced to $1^{\text {st }}$ order.
} 
the firm to grow its stock of capability and makes achieving future revenue objectives even easier. When operating in this virtuous direction the Capability Tipping loop creates a growing level of capability and competitive advantage. If, however, revenue falls below its target, firms engaged in earnings management may divert resources away from capability development in an effort to close the gap (the Make the Numbers loop). While this will increase revenue in the short run, it also reduces investment in capability. As the level of capability falls, it becomes more difficult for the firm to achieve its revenue target, thus increasing the pressure to shift resources towards revenue generation and away from capability development. In the extreme, capability can decline so much that the firm collapses reproducing the dynamics identified by those who lament the short-term focus of the capital markets. In the next section, we use the model to explore the conditions under which this is more or less likely to happen.

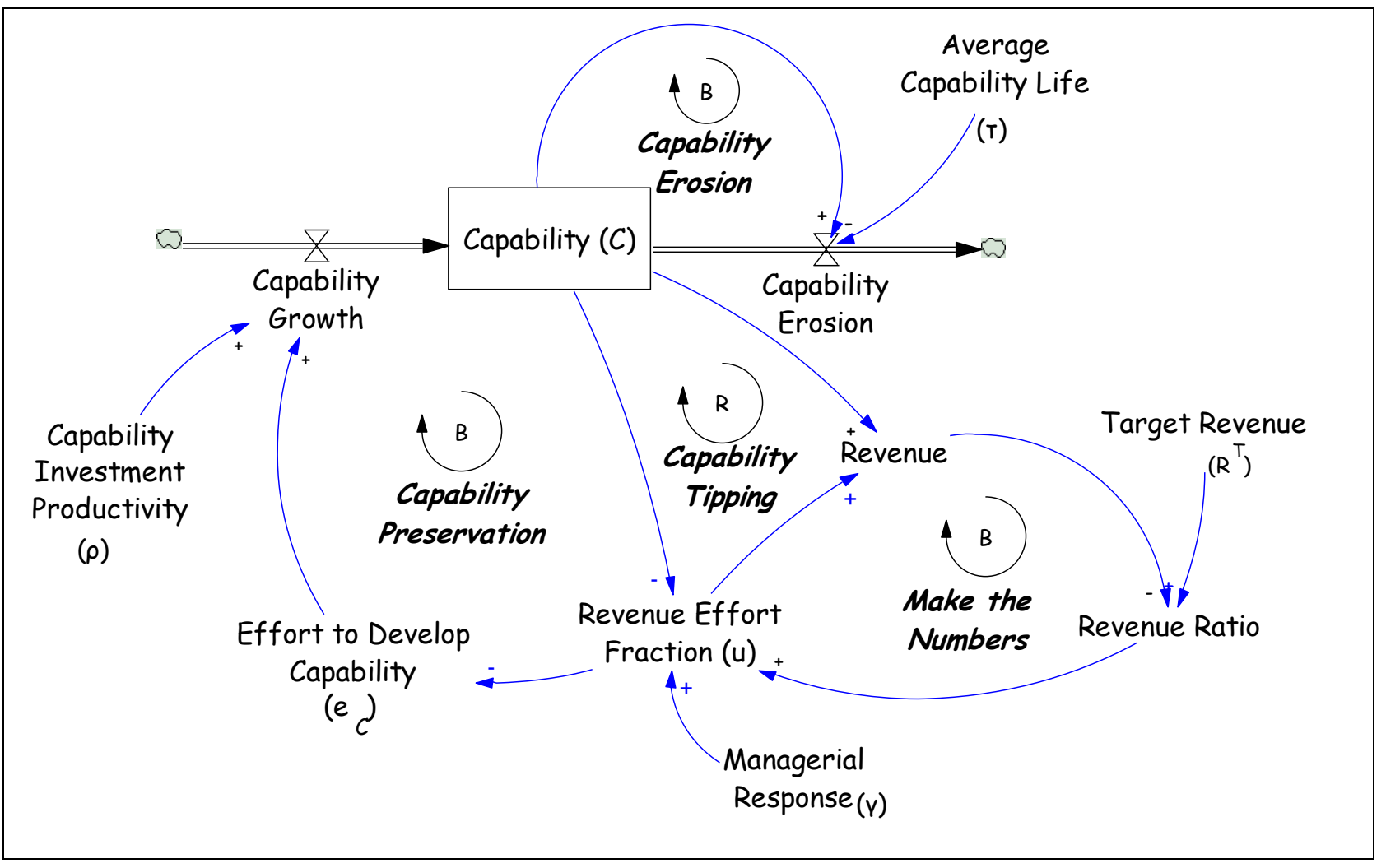

Figure 1-Model Overview 


\section{Model Analysis}

\subsection{Worse-Before-Better and Better-Before-Worse}

We begin the analysis by reproducing two of the dynamics highlighted in the qualitative literature on capability dynamics (e.g., Repenning and Sterman 2001): "Better before worse" and "Worse before better". Figure 2-a shows a set of model runs in which effort is initially split optimally $\left(u=u^{*}\right)$ between revenue generation and capability investment and then, in month ten, is rebalanced to focus "excessively" on generating short term revenue. We show three possible paths, each corresponding to a different increment of a short term focus. In each case, immediately following the shift, because capability does not immediately degrade, revenue temporarily grows above the steady state optimum. Later, however, as the reduced investment causes capability to erode, revenue begins to fall. Adjusting effort towards revenue generation thus creates a "better-before-worse" behavior pattern: by reducing investment in capability the firm can temporarily raise its revenue, but such gains come at the expense of future performance. This is the "milk the business" trajectory highlighted by those who worry about an excessive focus on short-term performance.

Conversely, Figure 2-b shows the revenue trajectories when the simulation starts with varying degrees of an overemphasis on revenue generation and, then, at month ten effort is rebalanced to match the optimal mix, $u^{*}$. In these cases revenue initially declines with the reduction in the effort dedicated to generating revenue. Later, as the additional effort dedicated to capability investment begins to pay off, revenue improves, eventually surpassing the initial level (since the effort balance is now optimal in steady state). This is the "worse-before-better" trade-off found in the innovation and process improvement literatures (e.g., Repenning and Sterman 2001): increased investment in assets and activities that build capability pays off only after depressing short term results. 


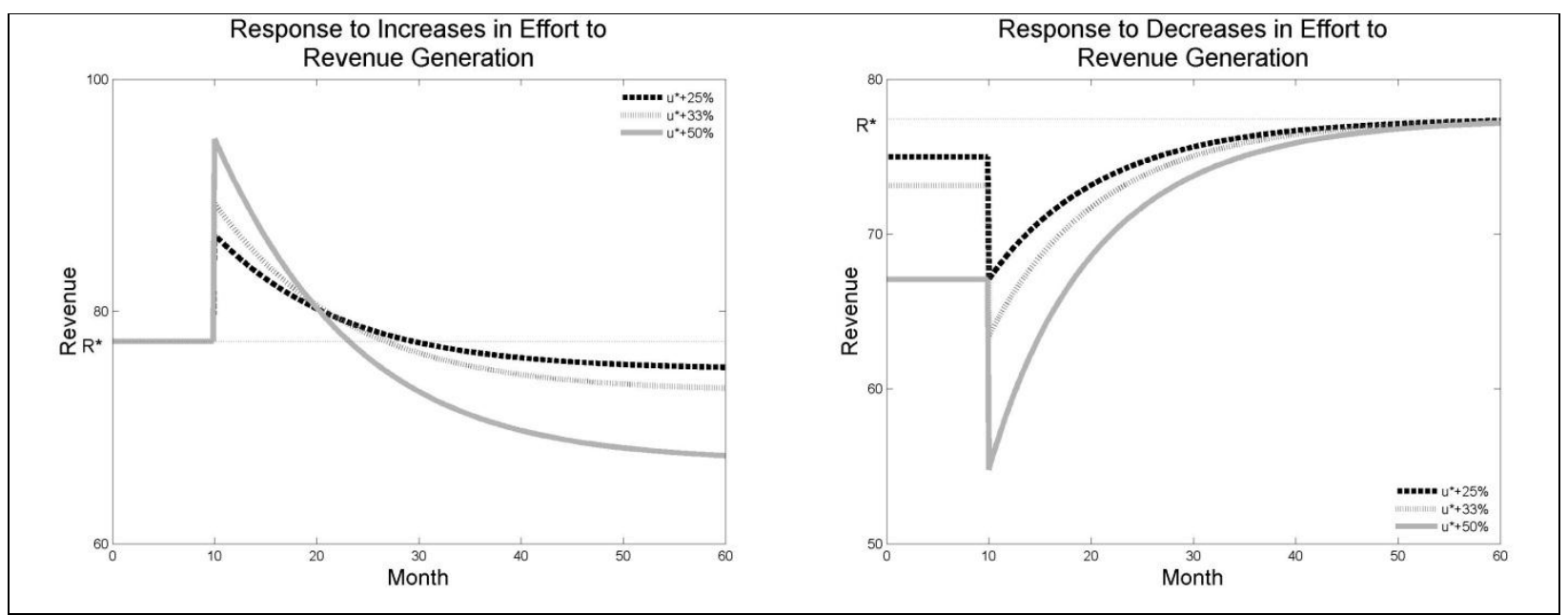

Figure 2- Better before worse and worse before better reference modes

As these results highlight, if investment in capability is usefully conceptualized as building assets that are subject to the processes of accumulation and erosion, then managers face an important temporal trade-off. Since the productive capabilities of these assets do not degrade immediately when investments in them are reduced, managers have some ability to adjust when revenue is actually earned. A manager facing a weak fourth quarter might, for example, choose to cut back on investment in training, maintenance or $\mathrm{R} \& \mathrm{D}$ in favor of revenue generation to meet earnings targets, planning to rebuild the consequent loss in capability later. Conversely, those who wish to push their organization to a higher level of performance by developing new capabilities must endure a period of low performance before their investments yield significant gains.

Note that these dynamics raise the agency concerns highlighted by Stein (1989) and others. A principal (or a shareholder) observing a performance decline has difficulty determining whether this decline is due to an increased investment in capability — which will pay off in the future — or to lack of ability on the part of the agent (or the management team). Conversely, principals observing a performance gain cannot determine whether it signals above average ability or simply results from the agent focusing on short run gains at the expense of long run performance. Stein (1989) suggests that in such cases managers will often "borrow" from the future at an unfavorable rate-akin to focusing on 
revenue at the expense of capability-- in an effort to demonstrate that they are neither shirking nor incompetent. Given their presumption of equilibrium, however, models in this tradition cannot analyze the disequilibrium dynamics that may result from an overemphasis on immediate revenue generation, particularly in the face of external shocks. In what follows we explore how managers' efforts to maintain steady earnings can have quite different effects depending on the state of the firm. While models like Stein (1989) predict a uniform degradation in performance as a result of the pressure to maintain short term results, our analysis shows that the influence of earnings management on performance can be nonlinear due to the existence of a critical threshold beyond which efforts to smooth earning shift from functional to pathological.

\subsection{Earnings Management and Tipping}

To analyze the dynamics of earnings management, we begin with a simple case in which two firms, one focused on delivering smooth earnings $(\gamma=1.75)$ and one focused on long run performance $(\gamma=.25)$, are exposed to two offsetting revenue shocks, one unfavorable (at month 10) and one favorable (at month 25). As shown in Figure 3-a, the firm focused on smoothing earnings responds to the negative shock by reallocating effort away from capability development towards revenue generation, and, consequently, the decline is revenue is modest and smaller than the shock that precipitated it. Capability falls and stays below its optimal level (recovering only asymptotically) until the positive shock. When the positive shock occurs, the firm allocates effort away from revenue generation and towards capability development, thereby returning the system to its optimal operating point. The capability-focused firm, in contrast, is less willing to divert resources away from investment and therefore experiences a larger decline in revenue (see Figure 3-b). Capability degrades only slightly and recovers quickly. Conversely, when the positive shock is experienced, the capability-focused firm passes the gains through to its owners rather than building a reserve of capability.

Consider how the external analysts, who can only observe revenue directly, might evaluate the two firms. Facing a sudden drop in capability (e.g. due to supply chain disruption; panels c and d) the 
capability-focused manager increases allocation to capability, suffers a significant short-term reduction in revenue, but is able to get back on track relatively quickly. In contrast the revenue-focused manager increases the allocation to revenue and avoids the sharp drop in revenue, at the expense of slower recovery of the capability. Both survive the exogenous shocks and generate similar amounts of cumulative revenue. The capability-focused firm, however, is likely seen by market observers as offering less reliable returns in comparison to its revenue-focused peer. In this example revenue smoothing has few costs and goes a long way towards alleviating the agency concerns faced by owners who cannot reliably observe capability or effort. We would thus expect that more revenue-focused heuristics (i.e. higher values of $\gamma$ in our setting) to be attractive for a notable fraction of managers.

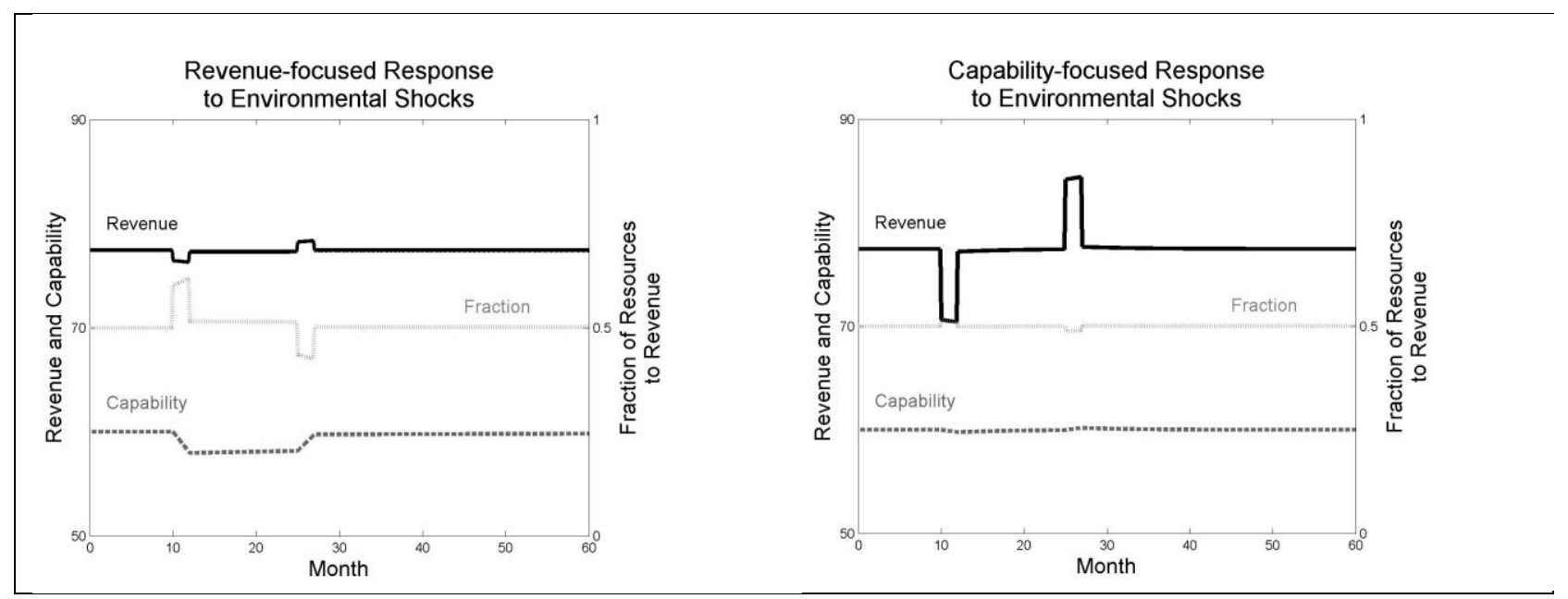

Figure 3-Response to temporary revenue shocks

Though the revenue heuristic has several desirable properties, a more complete analysis suggests that earnings management is not always so costless. To fully describe this system's dynamics we use the rate-level plot, a graph that relates the net rate of change in capability to the current level of capability (Strogatz 1994). In our formulation capability change partially depends on environmental shocks. To focus on the non-random structures however, we generate this plot by focusing on the deterministic components of change in capability. Thus the equation for the rate-level plot can be found by replacing equations 6.3 and 4 into 1 , and simplifying the results: 


$$
\dot{C}=h \rho\left(1-\operatorname{Min}\left(1, u^{*}\left(\frac{C^{*}}{C}\right)^{\gamma-1}\right)\right)-\frac{C}{\tau}
$$

The rate-level plot captures the evolution of firm's state (capability) by showing how the net rate of change in capability is a function of current capability level. The slope of the line indicates whether, in that region, the system is dominated by a negative (downwardly sloping) or positive (upwardly sloping) feedback loop. Intersections between the rate level plot and the $\mathrm{x}$-axis represent equilibria (since $\mathrm{dC} / \mathrm{dt}=0$ ) and the slope at the intersection determines the equilbrium's stability. If the slope is positive, the equilibrium is unstable — small perturbations will not be offset-- while a negative slope indicates an equilibrium that is locally stable — small perturbations will be offset by the system's dynamics.

The rate-level plot for the system we study can take one of two basic shapes depending on the sign of $\gamma-1$ term in eq. 11. The first possibility is shown in Figure 4 -a. If $\gamma \leq 1$ (indicating an emphasis on maintaining capability) then the plot is entirely downwardly sloping and intersects the x-axis at the optimal capability level. The system thus has only one, stable, equilibrium and shows no possibility of “tipping” or other more complex dynamics. From a feedback perspective, as long as $\gamma \leq 1$ the capability preservation loop is stronger than the Make the Numbers loop and, therefore, dominates the system's dynamics. As long as $\gamma \leq 1$ the system's dynamics will return it to the optimal capability level and there is no possibility of failure.

If $\gamma>1$, however, the rate level plot has a more complex form (Figure 4-b). Now the phase plot has three basic components, two downwardly sloping and one upwardly sloping, and crosses the x-axis three times indicating the system has three equilibria. Starting at the right, the first equilibrium is stable and occurs at the optimal capability level. In this region the balancing Capability Preservation feedback process again dominates the system's dynamics and, as indicated by the trajectory arrows, works to offset any departures from the optimal capability level. As capability declines however, the phase plot becomes positively sloped (between, in this case, capability levels of about 15 and 40) indicating a shift in dominance to the reinforcing Capability Tipping loop. In the region in which the phase plot is both 
upwardly sloping and lies above the axis, the Capability Tipping loop works in the upward (virtuous) direction - more capability makes it easier to hit the revenue target, thus enabling further investment in capability — and thus, as indicated on by the arrows on the phase plot, drives the system back to the target capability level.
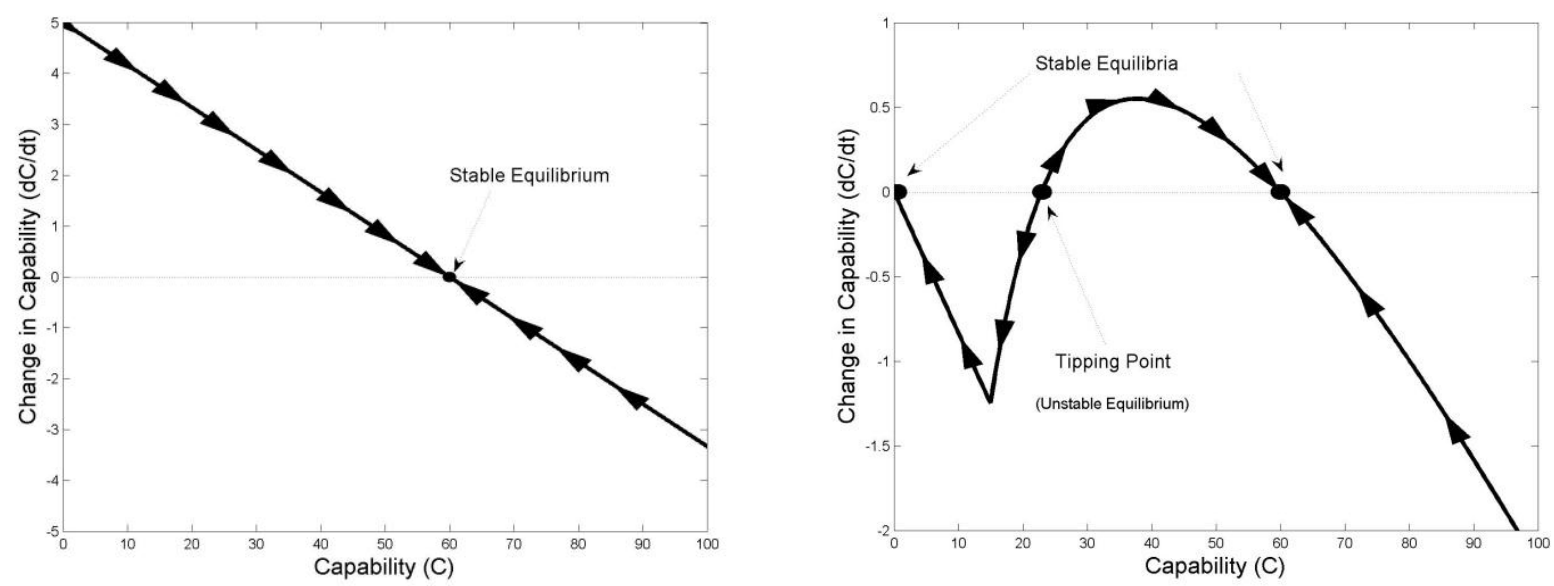

Figure 4-Sample Rate-Level plot for the System

Once the phase plot falls below the $\mathrm{x}$ axis, however, the dynamics change significantly. The Capability Tipping feedback remains dominant but now works in the downward (vicious) directiondeclining capability makes it more difficult to achieve the revenue target thus necessitating a further shift away from investment and towards revenue generation — and drives capability towards zero. The slope of the plot once again becomes negative when capability has fallen to the point where all of the firm's resources are required to hit the revenue target (in this example at a capability level of about 15). At this point investment in capability ceases and the negative Capability Erosion loop dominates the system's dynamics and drives capability to the second stable equilibrium at the origin.

The rate-level plot formalism makes the system's dynamics easy to characterize. The equilibrium at the right is stable and represents a firm at the optimal capability $\left(C^{*}\right)$ level. At this point, in steady state, the resource allocation is optimal $\left(u=u^{*}\right)$ and thus delivers the target revenue, $R\left(u^{*}, 0, C^{*}\right)$, in 
expectation. The local stability of this equilibrium implies that small perturbations will be offset by the system's dynamics (also indicated by the arrows pointing towards the equilibrium point). In other words, while in the neighborhood of this point, the specified decision rule will work to offset any randomness in revenue generation and thereby return the system to its optimal operating point. It is exactly this stability that allows our hypothesized firm to smooth earnings with little penalty. Redirecting resources to revenue generation (and thereby offsetting negatives shocks) causes capability to fall, but as long as capability remains in the stable region it will eventually return to the operating point.

Moving to the far left of Figure 4-b, there is a second stable equilibrium at the origin. At this point, investment has ceased, capability has fallen to zero, and essentially the firm has already failed. This equilibrium is also locally stable; once in its neighborhood, absent an additional intervention, the firm will be on a trajectory towards failure. Here, the revenue focus embodied in the decision rule (6.3), rather than being functional, drives the firm to ruin; the efforts of managers to maintain revenue trap the firm in a vicious cycle of declining capability and desperate efforts to boost revenue.

A third, unstable, equilibrium lies between the two stable ones. Due to its instability, even the smallest perturbation will move the system towards one of the two stable points, thus making it unlikely that the system would ever settle at this level of capability. Nonetheless, this point plays a critical role in determining the system's dynamics. As indicated by the arrows on the rate-level curve, it represents the point at which the utility of Capability Tipping loop changes direction. When operating at levels of capability above the unstable equilibrium, this feedback acts as a virtuous cycle and drives the system back to the desired operating point. In this region, managers' efforts to smooth earnings do not entail a long-term sacrifice in performance and capability will tend to revert to the optimal level. Once capability falls below the unstable equilibrium, however, the loop works as a vicious cycle-less capability, an increased focus on revenue and declining investment-- and the same decision rule now drives the firm towards failure. The unstable equilibrium thus represents a kind of "tipping point": As long as capability remains above it, the system remains stable and efforts to smooth earning can have considerable benefits 
and few costs. If, however, efforts to smooth earnings push capability below that critical threshold, then, absent an additional intervention or change in the decision rule, the firm will be on a trajectory towards failure.

The main insight that thus emerges from our analysis is that whether efforts to smooth earnings detract from performance is a matter of degree. As long as capability remains above the critical threshold captured by the unstable equilibrium, efforts to adjust earning have only a second-order impact on average performance. Once that threshold is crossed, however, the desire to smooth earnings become pathological as the efforts to maintain revenue come at the expense of the firm's long term viability. Of course, our analysis presumes that managers who cross this threshold continue to use the decision rule outlined in (6.3) and do not change their tendency to smooth earnings (represented by $\gamma$ ). This assumption undoubtedly simplifies real behavior; it seems likely that many managers would eventually realize that capability had fallen to a dangerously low level. If, however, managers only make this realization with a significant delay, then a firm that crossed its capability threshold could find itself in a vicious cycle of increasing emphasis on earning and declining investment in capability for some time before its leaders recognized that their efforts to manage earnings were threatening the firm's long term viability.

There are several reasons to believe that managers will not immediately recognize when their efforts to manage earnings have moved from functional to pathological. Most generally, learning is difficult in non-linear dynamic systems because local search and simple extrapolation are poor guides to anticipating outcomes (Sterman 1994). Systems with tipping dynamics are particularly challenging on this score because the system's response to inputs when operating above the threshold differ from the response once the threshold is crossed (see also Rudolph and Repenning 2002). Moreover managers who do realize that they have crossed the tipping threshold face the "worse-before-better" dynamics associated with an increased emphasis on capability that we described at the beginning of our analysis. Due to agency concerns, managers who are rewarded principally on short-term results may not be able to "afford" the price of rebalancing effort towards capability generation even if that was the right decision. 
Figure 5 shows two model runs that illustrate the difficulty of learning to manage in this system. In both cases a revenue-focused firm $(\gamma=1.5)$ begins with the optimal level of capability and is exposed to negative revenue shock, in the first case by $25 \%$, and in the second by $30 \%$.

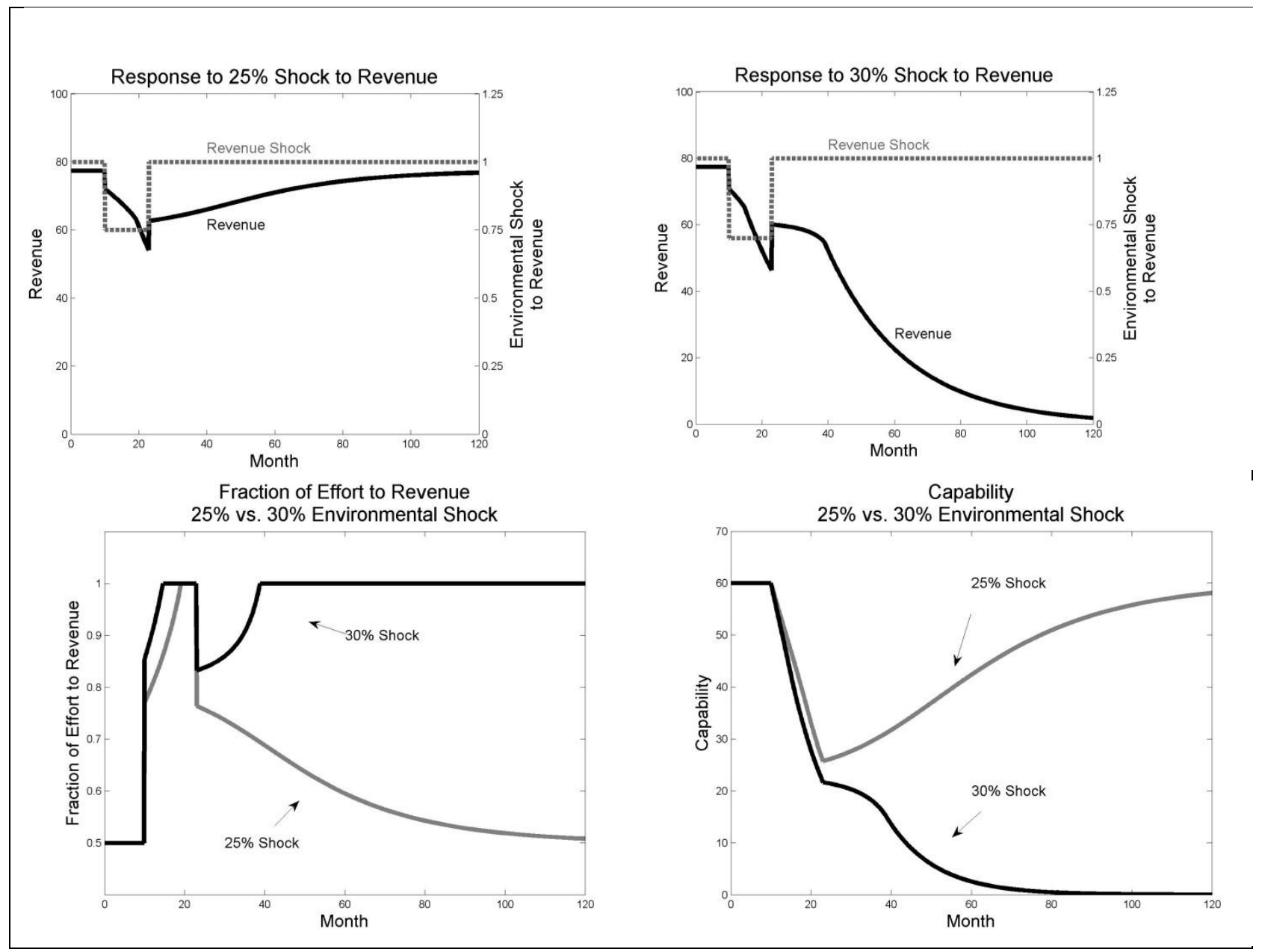

Figure 5- Response to 25\% and 30\% Environmental Shocks to Revenue

In the case of a $25 \%$ shock (Figure 5-a), revenue suffers, but increasing the effort allocated to revenue generation (Figure 5-c) partially offsets the reduction, keeping it below $25 \%$. Revenue declines during the "down period" as capability (Figure 5-d) begins to erode, but, once the shock is removed the system returns to the target revenue and capability levels. The manager of this hypothetical firm would likely be rewarded relative to her more capability-focused peers for exerting considerable "financial discipline" during a difficult set of business conditions. The outcome is quite different, however, when 
the environmental shock is slightly larger, in this case $30 \%$ instead of $25 \%$ ( Figure 5-b). Revenue initially follows a path similar to that in $25 \%$ shock as revenue management kicks in (Figure 5-c). However, the intensity of revenue management during the "down" year pushes the capability below the tipping threshold. Having passed the tipping point, managers' continued focus on revenue creates a vicious cycle of declining earnings, increased effort to revenue generations, and the erosion of the capability needed to generate those earnings (Figure 5-d). The reinforcing loop Capability Tipping thus "takes over" and drives the firm towards failure.

Note how past experience does little to reveal the location of the tipping threshold. Imagine a young manager in a cyclical industry charged with maintaining earnings through the inevitable down periods. During her first down turn, she might make relatively modest reallocations (well above the tipping threshold) of effort and the system would reward her for doing so. Based on that initial experience, her reallocations are likely to intensify in each subsequent cycle and she will be increasingly rewarded for doing so. Humans are, the word of psychologist Jim Reason, "furious pattern matchers" (Reason 1990) and this pattern is all too easy to identify: the more aggressive her efforts, the better her performance. Missing from this learning, however, is any sense that with each effort she is moving her organization closer to the tipping threshold. Only when the decline in capability begins to manifest (perhaps as an accident or a major product recall) will she have any sense of the full range of the system's dynamics. But even this experience can be attributed to a plethora of external causes and might need to be repeated several times to temper what she learned when operating on the other side of the tipping threshold.

Our analysis thus yields a candidate resolution to the puzzle of why managers' efforts to "make their numbers" can seem alternatively functional and pathological. Recognizing that capability behaves as a stock or level variable combined with the efforts of managers to offset environmental shocks to revenue generation creates a system with a tipping threshold. When operating above that threshold, efforts to manage earnings are a functional response to the capital market's desire for smooth earnings 
and lead to both reduced agency concerns and higher valuations. Moreover, operating above the threshold provides managers with powerful evidence concerning the utility of earnings management; the more they do it, the more they are rewarded by the external markets. Once that threshold is crossed, however, earnings management becomes a path to low performance. Whether or not the firm survives this type of decline will depend on its strength relative to its competitors, its institutional context (e.g., whether a government is willing to support it through a rebuilding period) and, how long it takes managers to recognize that a change of approach is in order.

\subsection{Comparative Dynamics}

The existence of a tipping threshold for $\gamma>1$ suggests that in the pursuit of stable earnings managers risk descending from a higher performance configuration into a vicious cycle of declining performance and eroding capability. As highlighted by the rate level plot the distance between the desired, stable, equilibrium and the tipping point determines how much "room" a manager has to smooth earnings. If the distance is large, then capability can decline significantly before the threshold is crossed. If the distance is small, however, then efforts to offset even a small revenue shock can push the system into the downward spiral of capability erosion. In this section we explore how the existence of the tipping point and the degree to which the distance between the two equilibria - or the likelihood that the firm will tip into “firefighting" - changes as a function of two key behavioral parameters: the firm's revenue focus, $\gamma$, and the degree to which the firm routinely under or overinvests in long term capability building. ${ }^{4}$

Changing revenue focus. The first parameter that influences the degree to which the system is prone to tipping is $\gamma$, the level of manager's focus on revenue vs. capability management. $\gamma$ can change between 0 and $1 / \beta$ ( $\beta=0.5$ in our simulations), where $0 \leq \gamma \leq 1$ reflects a capability-focused heuristic and $1<\gamma<1 / \beta$ a revenue-focused heuristic. In the previous analysis we set $\gamma$ to 1.5 , representing moderately intense focus

\footnotetext{
${ }^{4}$ Analytical characterization of the system is available in the online appendix S3. The capability erosion time $(\tau)$, capability investment productivity $(\rho)$, and total effort $(h)$ all have a similar, more minor, impact on the results, i.e. reducing $\tau$. $\rho$.h brings the tipping point closer to the stable equilibrium, and are not discussed in detail here.
} 
on smoothing earnings. In Figure 6, we show how the rate-level plot and the location of the tipping threshold change as managers increase their propensity to focus on delivering steady earnings.

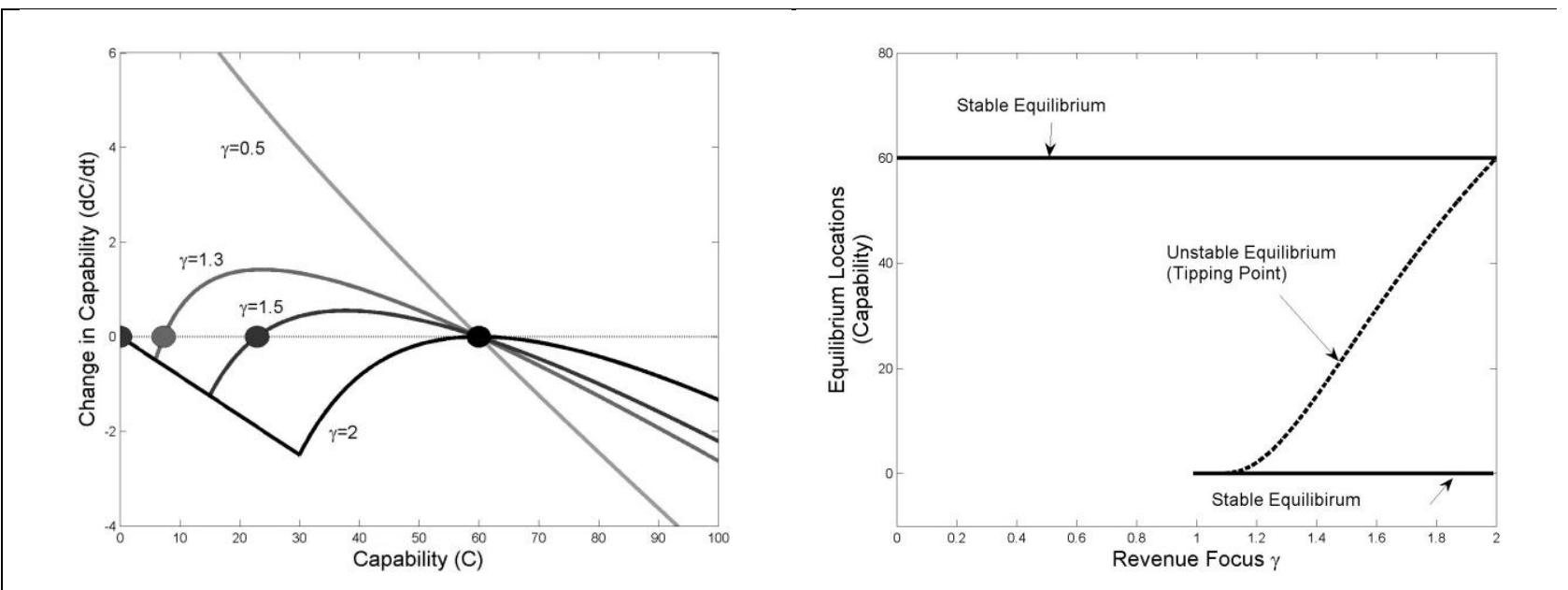

Figure 6- Sensitivity of system's dynamics to managerial response parameter $\gamma$.

As Figure 6-a suggests, strength of managers' response to revenue shortfalls plays a significant role in determine how robust the system is to tipping. The locations of the stable equilibria do not change since $\gamma$ only affects the out-of-equilibrium behavior, but as managers respond more aggressively to short falls in revenue (i.e. as $\gamma$ grows), the distance between the tipping threshold and the desired operating point declines (see Figure 6-b), implying that a smaller shock is required to push the system over the edge. Thus, the analysis suggests that managers who aggressively adjust short-run resource allocation to maintain revenue in the face of demand shocks run an increased risk of pushing their firms over the tipping threshold.

Biases in Effort Allocation. The second parameter that proves influential in determining the system's dynamics is the baseline allocation to revenue, $u^{*}$. So far we have assumed that in equilibrium, the managers choses the optimal allocation of effort $\left(u^{*}=\beta\right)$. The available evidence suggests, however, that such optimality is far from guaranteed. Studies in both manufacturing and new product development suggest that firms often over emphasize short-term revenue generation and undervalue capability 
development (Easton and Jarrell 1998; Pfeffer and Sutton 2000; Repenning 2001; Repenning and Sterman 2002; Rahmandad 2012). These studies identify several reasons for such biases ranging from individuallevel perceptual biases - revenue generation is far more salient and tangible than long term investments like capability development — to organizational level challenges — rewarding longer term investments in less tangible assets like "capability" is often more difficult than recognizing contributions to immediate revenue generation. Systematic under-investment in capability appears to often be the norm. Moreover, rational managers who discount future rewards decrease their base-line investment in capability by a term proportional to capability life $(\tau)$ multiplied by discount rate ( $r$ ) (See Appendix S2 for details). Therefore over-confidence in the resilience of capabilities (i.e. bias in $\tau$ estimate) and high discount rates (e.g. due to short-term managerial incentives) can also lead to biases in $u^{*}$.

Figure 7 shows how the rate level plot changes for revenue-focused managers, when the firm over/under invests in revenue generation. When firms systematically over-invest in capability development (here by 15\%) the phase plot moves up and the distance between the desired equilibrium and the tipping threshold increases. In this case, the system becomes more robust to temporary shocks but this robustness comes at the expense of revenue generation since, relative to the optimum, the firm is overinvesting in capability generation and thus receives lower revenue. Conversely, when the firm overinvests in revenue generation, the phase plot moves down and the distance between the desired equilibrium and the tipping threshold shrinks. In fact, as we show in the figure, if the over-investment is large enough, both the desired equilibrium and the tipping point disappear and the system displays a single trajectory, a downward spiral to failure. Thus, as firms place greater emphasis on immediate revenue generation, the distance between the stable equilibrium and the tipping threshold decreases and smaller shocks are required to push the firm into the downward spiral of declining capability. In the next section we extend this result to explore the interaction between environmental variability and a firm's tendency to focus on revenue. 


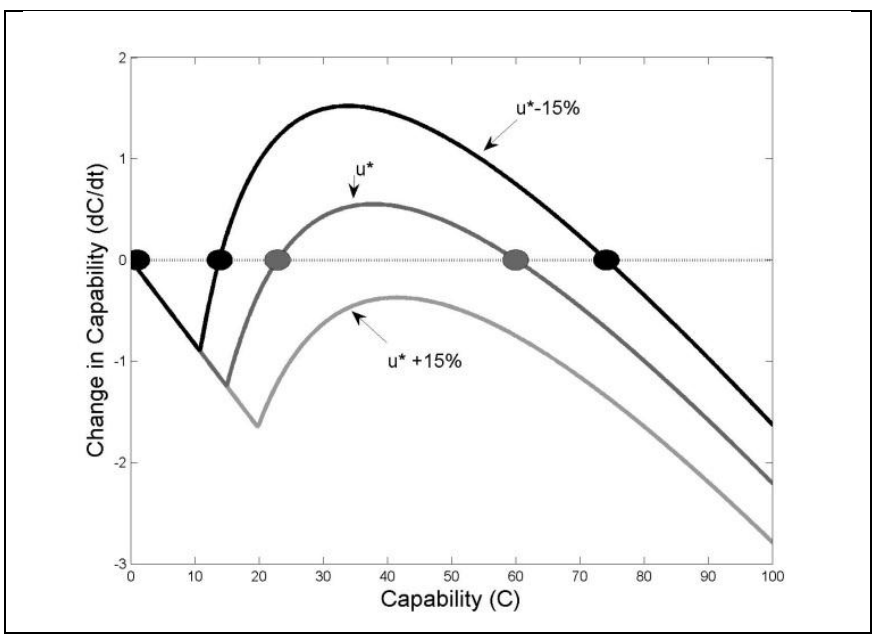

Figure 7- Impact of biases in baseline effort allocation.

\subsection{Extensions: Revenue Variability vs. Risk of Failure}

In this section we explore how variability in underlying demand and the system's time constants influence the firm's propensity to tip. To incorporate the effect of demand uncertainty we represent noise in demand by modeling $S$ - exogenous shocks to revenue - as a "pink" noise process, $\epsilon$, in which normally distributed white noise is exponentially smoothed to create first-order autocorrelation with time constant of $\xi$ and standard deviation $\sigma .^{5}$

$$
R=C^{(1-\beta)} e_{R}^{\beta}(1+\epsilon)
$$

We present large sample results in a moment, but to develop intuition for the main finding, consider two firms responding to the same pattern of demand. The first firm focuses on maintaining revenue and responds aggressively to any shortfall caused by a low demand realization $(\gamma=1.8)$, while the second firm focuses on maintaining capability $(\gamma=0.2)$.

Two Sample Paths- Figure 8-a shows one potential sample path for demand. When the two firms face this demand stream, the revenue-focused firm is able to maintain a steadier revenue stream (Figure 8-b).

\footnotetext{
5. See Sterman (2000) for an extended discussion concerning the utility of pink noise as a test input for continuous time simulation models. We truncate the noise term to stay between 0 and 2, keeping a symmetric, zero-mean, noise term while ensuring non-negative firm output.
} 
It does so by moving resources back and forth between capability development and revenue generation more rapidly than the capability-focused firm (Figure 8-c). The steadier earnings come at the expense of larger swings in capability level (Figure 8-d). However, as shown in panels e and f, since capability always remains above the tipping threshold, the revenue-focused firm displays superior performance. Its cumulative revenue over the simulation is essentially identical to that of the capability-focused competitor $^{6}$, but its revenue stream is substantially smoother. To the degree that the capital markets value predictable earnings, they would clearly value this stability and the revenue-focused management team would be viewed as superior. Before reaching a similar conclusion, however, consider a second realization of demand that has identical statistical properties to the first one.

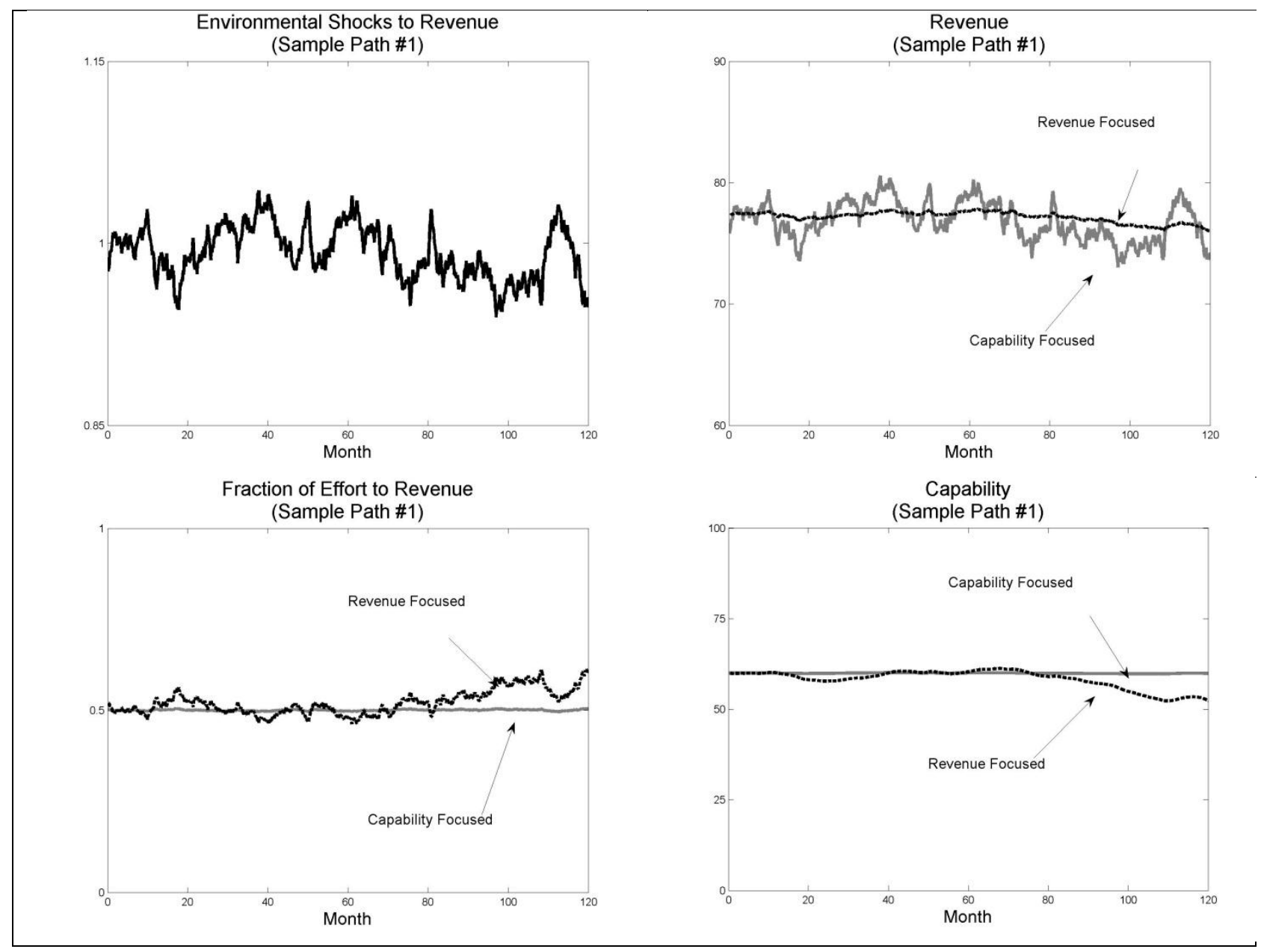

\footnotetext{
${ }^{6}$ Deviations from optimal path lead to very slight cumulative revenue penalty for the revenue-focused firm, but this loss is so small as not be visible in the figure.
} 


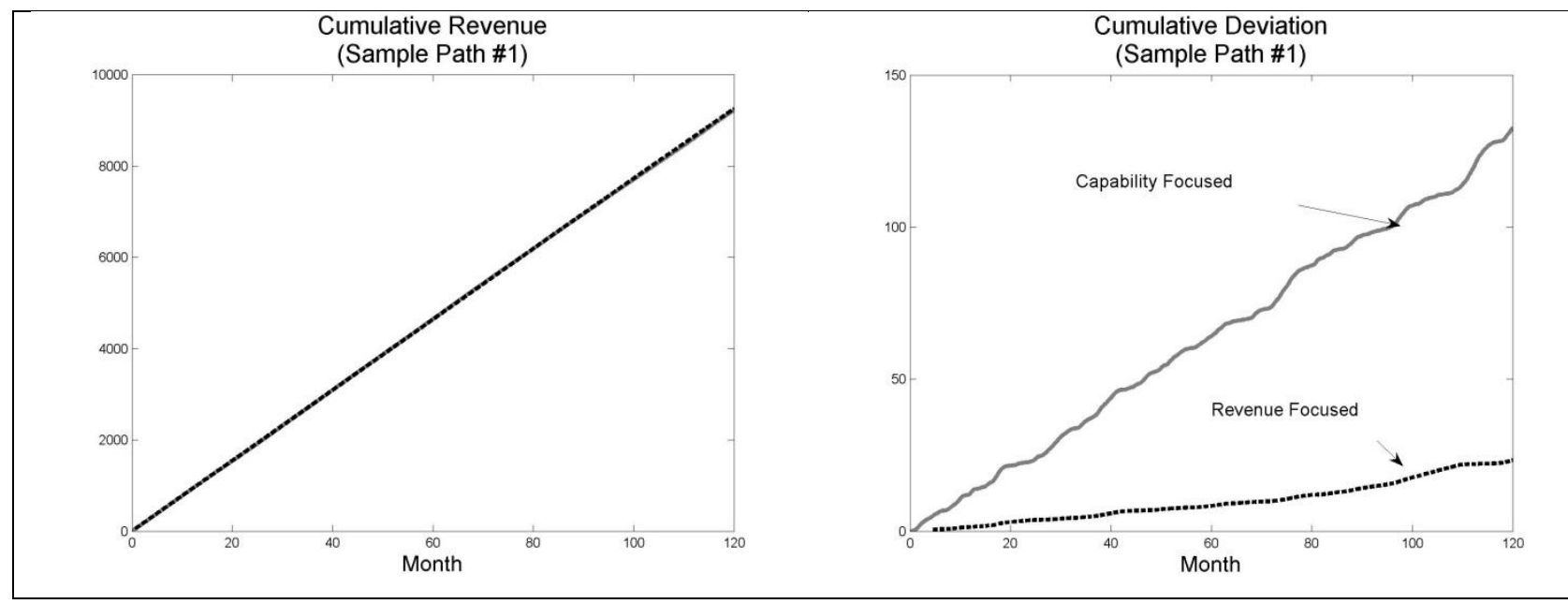

Figure 8- Revenue and capability focused outcomes; one demand realization with $\sigma=0.035 ; \xi=12$ months.

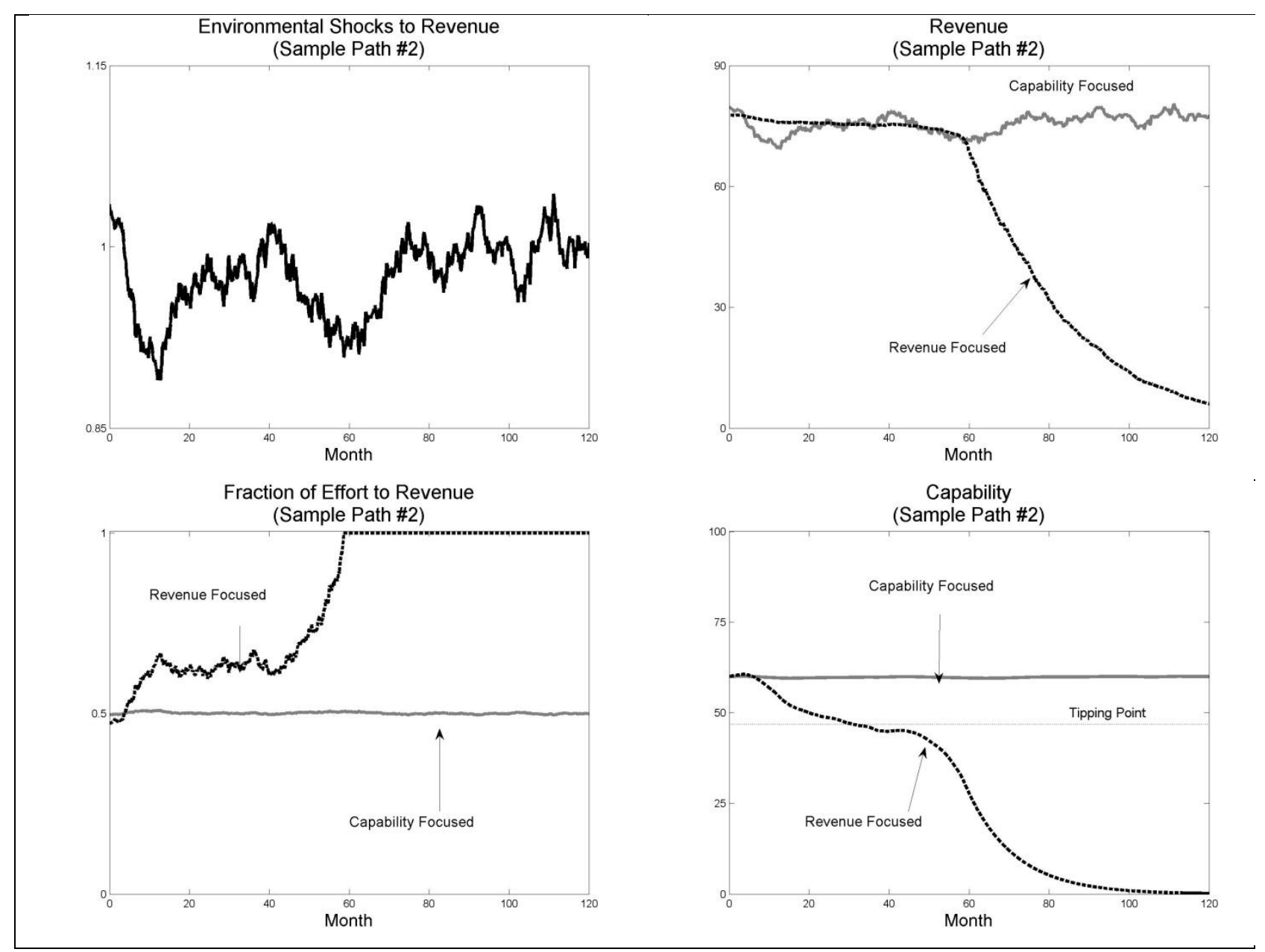




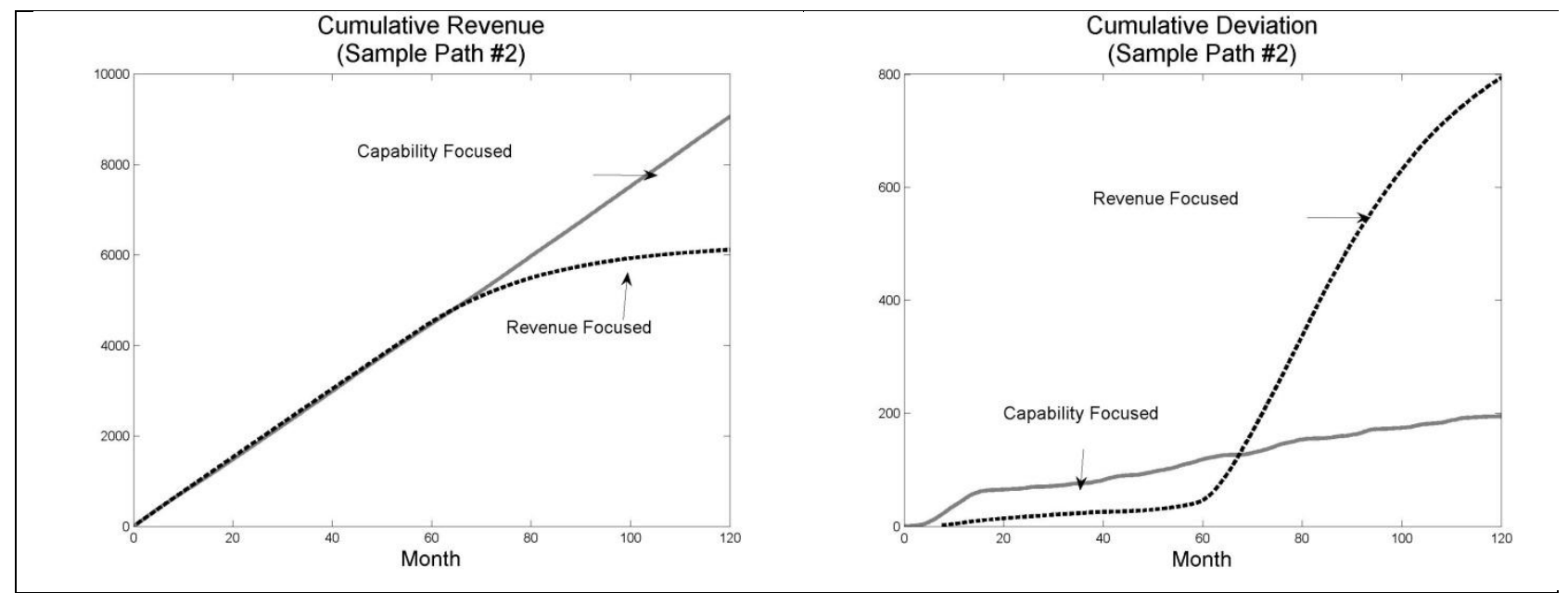

Figure 9- Revenue and capability focused outcomes; a different demand realization with $\sigma=0.035 ; \xi=12$ months.

Though the mean and variance are identical to the first realization, the second sample path is characterized by extended periods of low demand between months five and twenty, and then forty and seventy (Figure 9-a). During these periods, the revenue-focused firm works hard to maintain its revenue (Figure 9-b) by increasingly allocating effort towards additional revenue generation ((Figure 9-c). The strategy initially appears to be successful; during the first downturn the revenue-focused firm has higher revenue for more than a year. However, efforts to prop-up revenue during the period of low demand result in declining capability, which, in turn, requires more effort dedicated to revenue generation. Eventually, the revenue-focused firm falls below the tipping threshold and the firm's performance declines, significantly reducing revenue and increasing variability (panels e and f). In practice such a firm is likely to exit the market well before the end of simulated period, so the actual observations on the outcomes of such revenue-focused firms may be right-censored. Meanwhile, the capability focused firm, although experiencing higher revenue variability initially, survives throughout the simulation period and generates significant more cumulative revenue.

Large Sample Results. We first consider the interaction between firms' revenue focus, $\gamma$, and the degree of variability in demand $(\sigma)$. Figure 10 shows the results of a Monte Carlo analysis. The model was run 
for different managerial policies $(0 \leq \gamma \leq 2)$ under various levels of demand variability $(0 \leq \sigma \leq 0.5), 1000$ times for each combination of the two parameters. Contour plots report the fraction of firms that fail (panel a), and the average recent revenue variability for the firms that survive (panel b) ${ }^{7}$. We report results for the surviving firms (rather than the full sample) since results conditional on survival are easier to interpret; failure significantly reduces revenue and increases its variability, confounding, in the full sample, the day-to-day revenue outcomes with failure. Moreover, in practice firms that fail normally exit the market, thus reporting on survivors better replicates empirically observable samples.
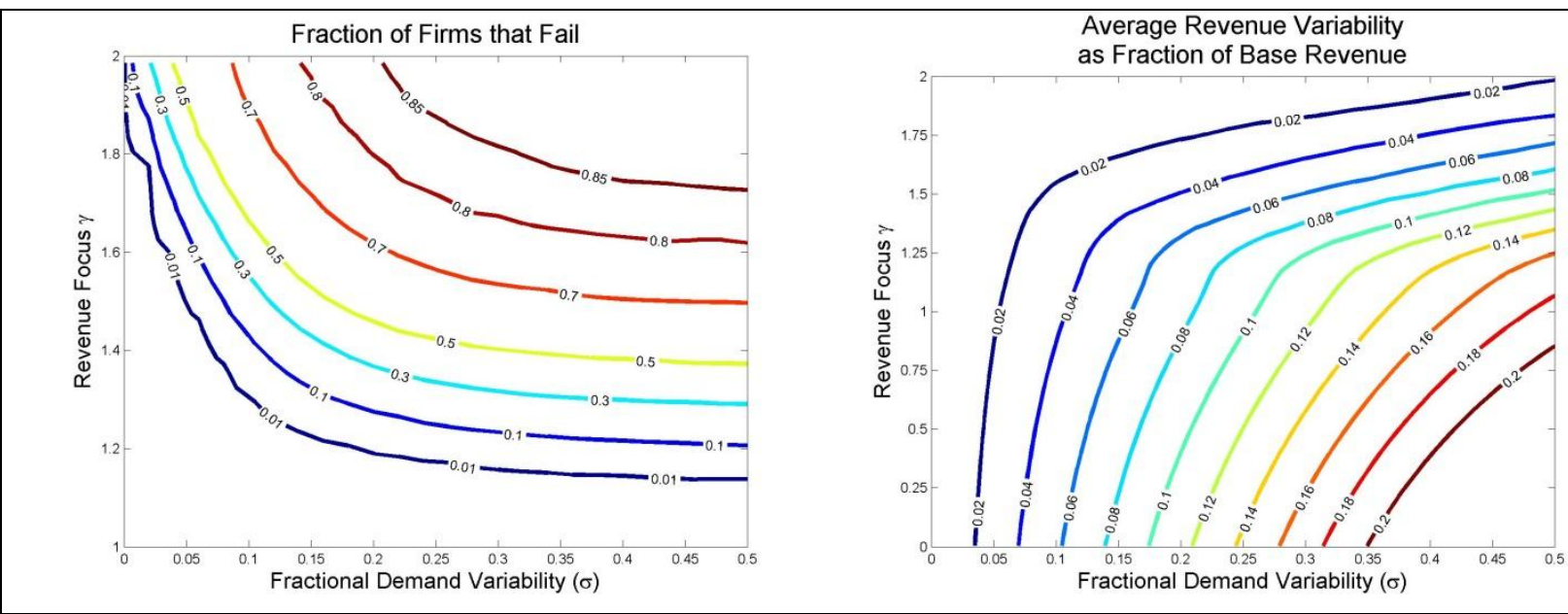

Figure 10-Fraction of firms that fail (a) and the average recent revenue variability of surviving firms (b) as a function of different demand variability and managerial policies.

As discussed in the section on tipping points, capability focused firms $(\gamma \leq 1)$ never fail thus Figure

10-a focuses on $\gamma>1$. Both higher demand variability, $\sigma$, and an increased focus on revenue are associated with higher failure rates. Moreover, the two effects interact: for low levels of demand variability, a revenue focus imposes only low to moderate risks. But as the environment becomes more volatile and the distance between stable equilibrium and tipping point shrinks (See Figure 6 discussion) the chance of failure grows significantly. In fact for volatile demand $(\sim \sigma>0.1)$ and moderate to high focus on revenue $(\sim \gamma>1.5)$ the majority of firms fail.

\footnotetext{
${ }^{7}$ Failure is defined as capability going below half the tipping value; the threshold of half is arbitrary and results are qualitatively similar for other plausible values. Revenue variability is measured as the average over simulation horizon of difference between revenue and its recent (12 month) exponential average.
} 
Note again the challenge of learning the right lessons in this environment. Among the surviving firms, a revenue focus reduces variability and increasingly so as the variation in demand grows (Figure 10-b). Managers who focus exclusively on capability $(\gamma=0)$ pass all the variability in the environment to their revenue, but managers who focus on revenue absorb some of that variability by changing capability levels. At the extreme $(\gamma=1 / \beta)$ revenue shows no variability until the firm crosses the tipping point. Consequently, among the surviving firms the average revenue shows little sensitivity to managerial policy and demand variability. In fact, for higher values of $\gamma$ the surviving sample disproportionately consists of "lucky" firms that have been exposed to long periods of better-than-average demand shocks. As a result these lucky firms accumulate high levels of capabilities, show little variability in revenue, and experience above average returns! The firms who are both lucky and aggressive in their efforts to manage earnings thus provide a very tempting role-model for aspiring managers.

Interestingly, persistence of environmental shocks $(\xi)$ and resilience of capabilities $(\tau)$ have identical (but inverse) impacts on the system's dynamics. The capability time constant, $\tau$, scales the time horizon for firm's dynamics and $\xi$ scales the time horizon for exogenous shocks to the system. Therefore the system's dynamics are indifferent to changing both parameters proportionately: the behavior of a firm with resilient capabilities (high $\tau$ ) exposed to highly correlated demand shocks (high $\xi$ ) takes more time to unfold, but is otherwise the same as a firm with short-lived capabilities exposed to less-correlated demand. Therefore we only analyze the large sample tradeoffs for demand variability correlation time, $\xi$, in Figure 11, using graphs similar to Figure 10, keeping in mind the implications for capability resilience.

Again, tipping dynamics and failure are absent in capability focused firms (Figure 11-a). For revenue-focused firms an increase in demand auto-correlation increases the risk of failure because periods of bad luck are more likely to persist, pushing the revenue-focused firms over its tipping points. The effect includes a subtle wrinkle: if more than half the firms are prone to failure due to a revenue focus, increasing autocorrelation actually helps reduce that fraction towards 50\%. In extreme, fully autocorrelated demand means $50 \%$ of the realizations consist of lucky firms with above average demand and 
thus no tipping, and the other 50\% will ultimately fail as long as $\gamma>1$. On the other hand, higher autocorrelation reduces recent revenue variability among surviving firms as it filters out short-term variation in demand, yet this impact is relatively small (panel b). The impact on average revenue (not reported) is small and limited to the bias created by over-sampling "lucky" firms among survivors. Overall, controlling for the variance in environmental shocks, firms exposed to more highly correlated shocks are more prone to failure, especially if they are focused on revenue. Similarly, and as a corollary, as capabilities become less resilient (a smaller $\tau$ ), the chance of failure in the face of correlated shocks also increased. Managers in environments with persistent shocks and short-lived capabilities may face a more acute challenge in learning to balance capability investments and revenue smoothing.
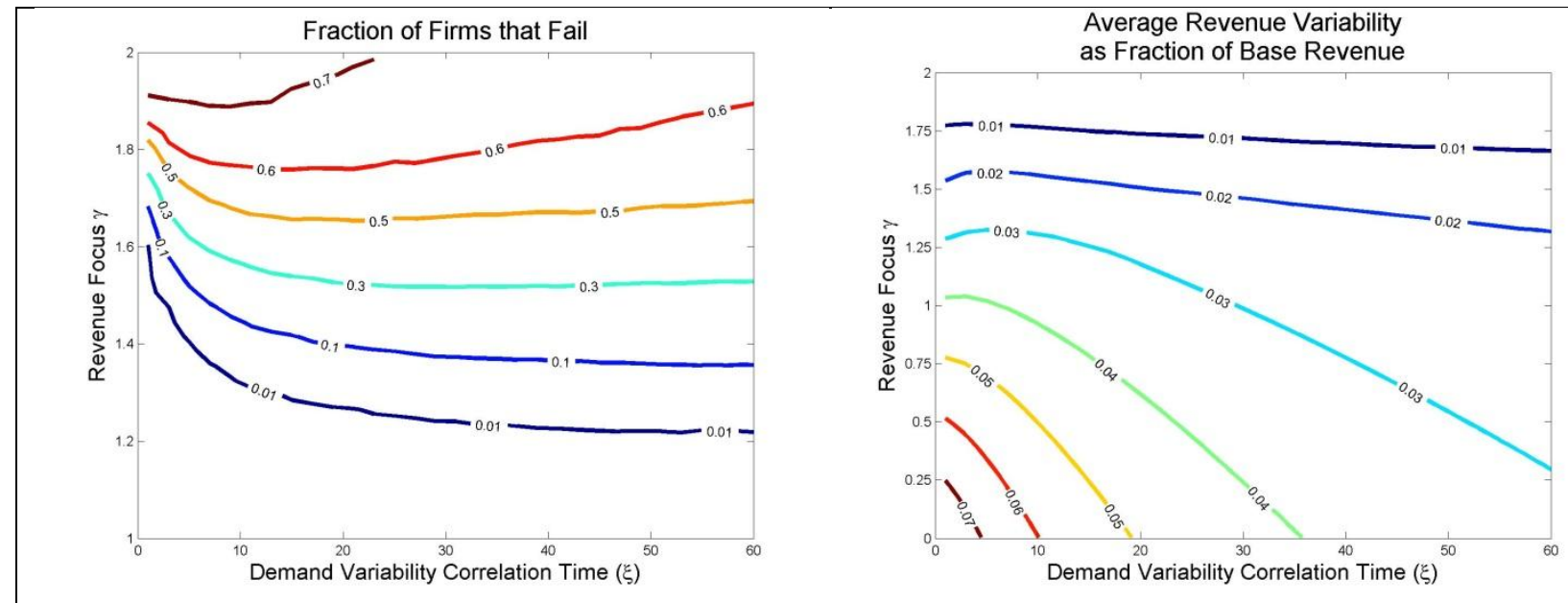

Figure 11- Fraction of firms that fail (a) and the average recent revenue variability of surviving firms (b) as a function of different demand correlation and managerial policies $(\sigma=0.1$ for these simulations).

\subsection{Discussion}

Analyzing our model thus suggests that whether managing earnings helps or hurts a firm turns on the intensity with which managers engage in it. If, as we hypothesize, capability behaves as a stock variable, then the firm can smooth some of the demand variation it faces without risking a significant decline in performance. Managing earnings in this situation offers several potential benefits including improved internal financial discipline and higher external investor confidence. If, however, the firm becomes too aggressive in its efforts to smooth earnings, it risks tipping into a vicious cycle of declining capability and 
a growing emphasis on short-term revenue generation. Whether crossing such a tipping threshold will result in firm failure or just an extended period of poor performance depends on both the institutional context and the speed with which the firm realizes the need to adjust its strategy. Our model thus reconciles the apparently puzzling tension in the literature between those who have shown that a focus on "managing earnings" is associated with better performance in the capital markets and those who have suggested it may be dangerously short sighted. In the space that remains we first address what is, perhaps, the central question raised by our analysis, namely "would managers ever be so naive as to get stuck in the trap we identify?" and then sketch an agenda for future research.

Would managers ever be sufficiently shortsighted as to allow a short-term focus to pull their firm into the vicious cycle of capability decline highlighted in our model? Unfortunately much research on human decision making in dynamics environments suggests that it is all too plausible for several reasons. First, while the benefits of focusing on earnings are realized relatively quickly — cutting the travel budget or canceling a development program can improve earnings within the given month or quarter-the costs - poorly operating equipment or an incompetent workforce — are only realized with a significant delay. Both experimental and field-based studies demonstrate that human decision makers do not perform well when their actions produce multiple outcomes that occur on different time scales. People tend to overweight those outcomes that happen quickly and to underweight those that occur with a delay (e.g., Sterman 1989; Brehmer 1992; Repenning and Sterman 2002). Managers finding themselves in a vicious cycle of declining capability and increasing earnings shortfalls are unlikely to make the connection between the challenges they face and their past actions and instead are likely to redouble their efforts to meet their short term targets (e.g., Staw 1976; Staw 1981; Azoulay, Repenning et al. 2010).

Second, because the system behaves very differently on the two sides of the tipping threshold, the dynamics associated with tipping greatly exacerbate the challenges associated with learning to balance the short and long run. As long as capability remains above the tipping threshold, efforts to manage earnings will have immediate benefits and few costs; once the threshold is crossed, however the costs are 
significant. The challenge of learning in this system is considerable. A new manager facing her first downturn in demand might be fairly modest in her initial attempts to manage earnings, perhaps restricting travel or temporarily cutting training budgets to offset low revenue. These efforts are likely to be "successful" - she will meet her targets despite the downturn--thus providing powerful feedback confirming the wisdom of her efforts. During the next down period, she is likely to be even more strict (building on her previous success), perhaps cutting the maintenance or R\&D budgets, hoping to demonstrate further her commitment to maintaining profitability. And again, these efforts are likely to be recognized and rewarded, providing additional positive reinforcement. This cycle of experimentation with increasingly aggressive measures and positive reinforcement will continue until capability is pushed below the critical threshold, whereupon performance will begin to decline despite her continued efforts. However, having experienced several rounds of success with a strategy that cuts the resources devoted to investing in capability, our hypothetical manager will require compelling evidence as to the error in her ways before revisiting her strategy. Capability, in the meantime, may have fallen to a dangerously low level.

The third factor making life difficult for managers is that it is usually difficult to measure or reward efforts to build "capability." Decision makers tend to focus on cues that are both salient and tangible (Einhorn and Hogarth 1985; Einhorn and Hogarth 1986). While quarterly earnings satisfy both of these criteria, most capabilities do not. Managers are thus unlikely to be aware that the firm's "stock" of capability is fluctuating dangerously. Several studies suggest, for example, that major industrial accidents are often preceded by extended periods of inadequate investment in both training and mechanical integrity (e.g., Baker, Gibbons et al. 2002; Columbia Accident Investigation Board 2003). Capability in these settings had been allowed to fall precipitously, but because accidents don't happen every day, recognizing the costs of such a decline was difficult until the lack of capability finally translated into a very visible accident. 
Our analysis thus opens several avenues for further research. It suggests, for example, that firms in settings in which capability is more easily measured, or in which the risks of tipping are more widely understood, are less likely to sacrifice the future in favor of smoother earnings and are less likely to be punished by the capital markets for not doing do. Most intriguingly, we believe, it reinforces the idea that firms able to use "relational" contracts based on more "subjective" assessments to measure and reward their managers may be able to outperform their competition. A long literature that includes Holmstrom and Milgram's (1991) seminal analysis of incentives in "multi-task" environments suggests that, in the absence of relational contracts, high-powered incentives can produce significant distortions when one activity is more easily measured than another. Given that short-term revenue is much easier to measure objectively than capability, this dynamic is likely to reinforce the tendency of managers to focus on current performance. If, however, managers and employees can develop an effective relational contract (e.g., Bull 1987; Baker, Gibbons et al. 2002), they can complement the objective measures of performance inherent in "making the numbers" with subjective measures that attempt to capture the employee's contribution to capability development and maintenance. Such a mechanism may, to a degree, allow managers to "have their cake and eat it too", to reap some of the benefits of high powered incentives — extra effort, financial discipline, steadier earnings and better access to capital—without the risk of tipping their firm into the vicious cycle of declining capability and increased pressure to meet earnings. We thus suspect that a key source of above average performance might be the differential ability of firms to create relational contracts that incorporate subjective evaluations of capability. Gibbons and Henderson (2010) present some preliminary research exploring this idea, but it remains tantalizingly underdeveloped.

An illustrative example of this kind of incentive scheme in action is provided by Jack Welch's recent description of his practice during his time as GE's CEO (Welch and Welch 2005). While GE had a notoriously performance-focused culture, GE's compensation scheme under Welch's tenure increasingly incorporated a subjective evaluation of how each manager performed with respect to the company's 
“values." Critically, GE's definition of values extended far beyond that suggested by common usage. While "values" typically include things like trust and integrity, Welch expanded the definition to include those behaviors that were core to maintaining the long-term performance of the business. As he wrote, “... (at GE) values are just behaviors - specific, nitty gritty, and so descriptive that they leave little to the imagination (Welch and Welch 2005)." These "values" included several measures of capability that would ultimately translate to long-term success including customer focus, product and service quality, and the development of intellectual capital. Thus, during his tenure GE employees were evaluated both on their ability to "hit their numbers" and on their ability to maintain and develop critical capabilities. Further, Welch reports learning the hard way to be wary of employees that made their numbers but did not display GE's values. Invariably, he reports, those employees were achieving their results by sacrificing key capabilities. "Those people,” he said, “...kill companies (Welch 2008).” While GE’s remarkable performance during Welch's extended tenure undoubtedly had several sources, the ability to mix a strong performance focus with an emphasis on capability development may have been an important factor, creating an organization capable of delivering steady performance without succumbing to the vicious cycle of capability decline.

\section{Conclusion}

Steady and reliable earnings bring many advantages to the firms that deliver them. Share prices rise, capital costs decline, and bonuses become both bigger and more likely. Such firms grow faster and attract more talented people to manage that growth. Despite these benefits, both scholars and practitioners have long been critical of the short-term focus that often characterizes western managers. Our model suggests that the solution to this seeming paradox lies in the fundamentally non-linear nature of any enterprise dependent on a stock of capability: above a given threshold earnings management is relatively harmless, but below it, it can be disastrous. We hope that future research will explore both the degree to which this model is supported empirically and the hypothesis that the ability to avoid tipping through the use of 
relational contracts that balance attention to both short and long term investments may be a critical source of competitive advantage.

\section{References}

Azoulay, P., N. P. Repenning, et al. (2010). "Nasty, Brutish, and Short: Embeddedness Failure in the Pharmaceutical Industry." Administrative Science Quarterly 55(3): 472-507.

Baker, G., R. Gibbons, et al. (2002). "Relational contracts and the theory of the firm." Quarterly Journal of Economics 117(1): 39-84.

Baker, J., F. Bowman, et al. (2007). The Report of the BP U.S. Refineries Independent Safety Review Panel.

Barth, M. E., J. A. Elliott, et al. (1999). "Market rewards associated with patterns of increasing earnings." Journal of Accounting Research 37(2): 387-413.

Bartov, E. (1993). "The Timing of Asset Sales and Earnings Manipulation." Accounting Review 68(4): 840-855.

Bartov, E., D. Givoly, et al. (2002). "The rewards to meeting or beating earnings expectations." Journal of Accounting \& Economics 33(2): 173-204.

Benner, M. J. (2007). "The incumbent discount: Stock market categories and response to radical technological change." Academy of Management Review 32(3): 703-720.

Benner, M. J. (2010). "Securities Analysts and Incumbent Response to Radical Technological Change: Evidence from Digital Photography and Internet Telephony." Organization Science 21(1): 42-62.

Bhojraj, S., P. Hribar, et al. (2009). "Making Sense of Cents: An Examination of Firms That Marginally Miss or Beat Analyst Forecasts." Journal of Finance 64(5): 2361-2388.

Bowen, R. M., L. DuCharme, et al. (1995). "Stakeholders' implicit claims and accounting method choice." Journal of Accounting \& Economics 20(3): 255-295.

Brav, A., J. R. Graham, et al. (2005). "Payout policy in the 21st century." Journal of Financial Economics 77(3): 483-527.

Brehmer, B. (1992). "Dynamic Decision-Making - Human Control of Complex-Systems." Acta Psychologica 81(3): 211-241.

Bull, C. (1987). "The Existence of Self-Enforcing Implicit Contracts." Quarterly Journal of Economics 102(1): 147-159.

Burgstahler, D. and I. Dichev (1997). "Earnings management to avoid earnings decreases and losses." Journal of Accounting \& Economics 24(1): 99-126.

Christensen, C. M. (1997). The innovator's dilemma : when new technologies cause great firms to fail. Boston, Mass., Harvard Business School Press.

Columbia Accident Investigation Board (2003). Columbia Accident Investigation Report. Burlington, Ontario, Apogee Books.

Dallas, L. (2011). "Short-Termism, the Financial Crisis, and Corporate Governance." Journal of Corporation Law 37: 264.

Dierickx, I. and K. Cool (1989). "Asset Stock Accumulation and Sustainability of Competitive Advantage." Management Science 35(12): 1504-1511.

Drucker, P. (1986). A crisis of capitalism. Wall Street Journal. (September 30): 31.

Dustmann, C., B. Fitzenberger, et al. (2014). "From Sick Man of Europe to Economic Superstar: Germany's Resurgent Economy." Journal of Economic Perspectives 28(1): 167-188. 
Easton, G. S. and S. L. Jarrell (1998). "The effects of total quality management on corporate performance: An empirical investigation." Journal of Business 71(2): 253-307.

Einhorn, H. J. and R. M. Hogarth (1985). "Ambiguity and Uncertainty in Probabilistic Inference." Psychological Review 92(4): 433-461.

Einhorn, H. J. and R. M. Hogarth (1986). "Judging Probable Cause." Psychological Bulletin 99(1): 3-19.

Farrell, K. A. and D. A. Whidbee (2003). "Impact of firm performance expectations on CEO turnover and replacement decisions." Journal of Accounting \& Economics 36(1-3): 165-196.

Gibbons, R. and R. Henderson (2010). What do managers do? Exploring Persistent Performance Differences among Seemingly Similar Enterprises. The Handbook of Organizational Economics. R. Gibbons and J. Roberts. Princeton and Oxford, Princeton University Press: 680-731.

Graham, J. R., C. R. Harvey, et al. (2005). "The economic implications of corporate financial reporting." Journal of Accounting \& Economics 40(1-3): 3-73.

Gunny, K. A. (2010). "The Relation Between Earnings Management Using Real Activities Manipulation and Future Performance: Evidence from Meeting Earnings Benchmarks." Contemporary Accounting Research 27(3): 855-+.

Haldane, A. G. (2010). Patience and Finance. Oxford China Business Forum. Beijing.

Healy, P. M. and J. M. Wahlen (1999). "A review of the earnings management literature and its implications for standard setting." Accounting Horizons 13(4): 365-383.

Helfat, C. E. (2007). Dynamic capabilities : understanding strategic change in organizations. Malden, MA, Blackwell Pub.

Holmstrom, B. and P. Milgrom (1991). "Multitask Principal Agent Analyses - Incentive Contracts, Asset Ownership, and Job Design." Journal of Law Economics \& Organization 7: 24-52.

Ingrassia, P. (2010). Crash Course: The American Automobile Industry's Road to Bankruptcy and Bailout - and Beyond. New York, Random House.

Laverty, K. J. (1996). "Economic "short-termism": The debate, the unresolved issues, and the implications for management practice and research." Academy of Management Review 21(3): 825-860.

Peek, J. and E. S. Rosengren (2005). "Unnatural selection: Perverse incentives and the misallocation of credit in Japan." American Economic Review 95(4): 1144-1166.

Pfeffer, J. and R. I. Sutton (2000). The knowing-doing gap : how smart companies turn knowledge into action. Boston, Mass., Harvard Business School Press.

Rahmandad, H. (2012). "Impact of Growth Opportunities and Competition on Firm-Level Capability Development Trade-offs." Organization Science 23(1): 138-154.

Repenning, N. P. (2001). "Understanding fire fighting in new product development." The Journal of Product Innovation Management 18: 285-300.

Repenning, N. P. and J. D. Sterman (2001). "Nobody ever gets credit for fixing problems that never happened: Creating and sustaining process improvement." California Management Review 43(4): 64-+.

Repenning, N. P. and J. D. Sterman (2002). "Capability traps and self-confirming attribution errors in the dynamics of process improvement." Administrative Science Quarterly 47(2): 265-295.

Rudolph, J. W. and N. P. Repenning (2002). "Disaster Dynamics: Undrstanding the Role of Quantity in Organizational Collapse." Administrative Science Quarterly 47: 1-30.

Rummel, N. (2008). Short-term earnings focus led to Wall Street woes, former SEC chief Donaldson says. Financial Week. Available at http://www.financialweek.com/apps/pbcs.dll/article?AID=/20080917/REG/809179981/1038/EX CLUSIVES. 
Staw, B. M. (1976). "Knee-deep in the Big Muddy: A study of escalating commitment to a chosen course of action." Organizational Behavior and Human Performance 16: 27-44.

Staw, B. M. (1981). "The escalation of commitment to a course of action." Academy of Management Review 6: 577-587.

Stein, J. C. (1989). "Efficient Capital-Markets, Inefficient Firms - a Model of Myopic CorporateBehavior." Quarterly Journal of Economics 104(4): 655-669.

Sterman, J. (2000). Business dynamics: systems thinking and modeling for a complex world. Boston, McGraw-Hill/Irwin.

Sterman, J. D. (1989). "Modeling Managerial Behavior - Misperceptions of Feedback in a Dynamic Decision-Making Experiment." Management Science 35(3): 321-339.

Sterman, J. D. (1994). "Learning in and about complex systems." System Dynamics Review 10(2-3): 91330.

Strogatz, S. H. (1994). Nonlinear dynamics and Chaos : with applications to physics, biology, chemistry, and engineering. Reading, Mass., Addison-Wesley Pub.

The Aspen Institute (2009). Overcoming Short-termism: A Call for a More Responsible Approach to Investment and Business Management. September 9, 2009, The Aspen Institute Business and Society Program.

Welch, J. (2008). Unpublished Personal Interview.

Welch, J. and S. Welch (2005). Winning. New York, HarperBusiness Publishers.

Williams, H. (1980). The Economy and the Future-The Tyranny of the Short-Run. An address given to the Commonwealth Club of San Francisco. 21 November. Available at http://www.sec.gov/news/speech/1980/112180williams.pdf. 
Online Appendix to Accompany the Paper:

MAKING THE NUMBERS?

“SHORT TERMISM" \& THE PUZZLE OF ONLY OCCASIONAL DISASTER

\section{S1- The finite horizon optimal allocation}

The optimal control problem for maximizing expected revenue in our problem can be written as maximizing the expected revenue subject to the dynamics of the system and the budget constraint:

$$
\operatorname{Max} \int_{t=0}^{t=T} E(R) d t
$$

Subject to:

$$
\begin{aligned}
& \frac{d C}{d t}=e_{C} \rho-\frac{C}{\tau} \\
& C(0)=C_{0} \\
& \alpha+\beta=1 \\
& 0 \leq u \leq 1
\end{aligned}
$$

To solve this problem we can set up the present value Hamiltonian with the co-state variable $\lambda$ which represents the shadow price of the capability at any point in time. Noting that environmental shock to the revenue, $S$, has a mean of zero and is not correlated with the other component of revenue and is zero-mean, we have $E(R)=C^{\alpha} e_{R}^{\beta}$, and thus we find a rather simple Hamiltonian function:

$$
H(C, u, t)=C^{\alpha} e_{R}^{\beta}+\lambda\left(e_{C} \rho-\frac{C}{\tau}\right)
$$

The necessary conditions for finding the optimal allocation policy, $u$, is:

$$
\frac{\partial H}{\partial u}=0
$$




$$
\begin{aligned}
& \frac{\partial H}{\partial C}=-\frac{d \lambda}{d t} \\
& \lambda(T) C(T)=0
\end{aligned}
$$

These conditions are also sufficient because the Hamiltonian is concave with respect to $u$ and $C$ for feasible values of $C$ and $u$. Solving the first constraint we find the following optimal allocation fraction:

$$
u_{D y n}=\operatorname{Min}\left(1,\left(\frac{\beta}{\lambda h \rho}\right)^{\frac{1}{1-\beta}} C\right)
$$

After replacing the optimum allocation in the second condition, the dynamics of co-state variable is described by the following differential equation:

$$
\frac{d \lambda}{d t}=\frac{\lambda}{\tau}-(1-\beta)\left(\frac{\beta}{\lambda h \rho}\right)^{\frac{\beta}{1-\beta}}
$$

Solving this differential equation (using Bernoulli method) we get the following time trajectory for the shadow price of capability, $\lambda$ :

$$
\lambda(t)=\left(\frac{\tau(1-\beta)}{\left(\frac{h \rho}{\beta}\right)^{\frac{\beta}{1-\beta}}}+K e^{\frac{t}{\tau(1-\beta)}}\right)^{1-\beta}
$$

Using the end state condition $(\lambda(\mathrm{T})=0$ ) we can solve for the constant $\mathrm{K}$ which gives the analytical expression for the time trajectory of $\lambda$ for any time horizon and combination of parameters.

$$
K=\frac{-\tau(1-\beta)}{\left(\frac{h \rho}{\beta}\right)^{\frac{\beta}{1-\beta}} e^{\frac{T}{\tau(1-\beta)}}}
$$

Inspecting the results, we note that this constant term is negative, and very small as long as $\mathrm{T}>\tau(1-$ $\beta$ ), that is, the time to end of horizon is appreciably smaller than the time constant for the erosion of capability. Therefore $\lambda$ is almost constant until we get fairly close (relative to $\tau$ ) to the end of 
investment horizon (T), at which time the shadow price starts to decline precipitously (note the exponential term in equation for $\lambda$ ), leading to increasing allocation of resources to revenue generation and a decline of capability, until at exactly time $\mathrm{T}$ the shadow price and capability stocks both become zero.

Therefore, assuming $\mathrm{T}>\tau(1-\beta)$, we can find a constant shadow price of capability that applies for a large section of our time horizon:

$$
\frac{d \lambda}{d t}=0 \Rightarrow \lambda=\left(\frac{\tau(1-\beta)}{\left(\frac{h \rho}{\beta}\right)^{\frac{\beta}{1-\beta}}}\right)^{1-\beta}
$$

Replacing $\lambda$ with this steady state value in equation for $u_{D y n}$ and simplifying the equations we get the following expression for the approximate optimal control allocation:

$$
u=\operatorname{Min}\left(1, u^{*} \frac{C}{C^{*}}\right)
$$

This simple expression suggests that optimal allocation in the dynamics case is 1) consistent with the steady state allocation, that is, if capability is at the steady-state optimal level, the allocation will be the same as steady state. 2) Variations of the optimal path in capability are compensated for by linear shifts in the allocation fraction: When capability falls short of the optimal steady state value, the allocation favors capability investment, while too much capability (relative to steady state) will lead to more effort (than steady state optimal) being allocated to revenue generation. Note that the heuristic used in our paper simplifies to this function when $\gamma=0$.

\section{S2- The infinite horizon optimal allocation}

The infinite horizon optimal control problem with discounted revenue can be written as: 


$$
\operatorname{Max} \int_{t=0}^{t=\infty} e^{-r t} E(R) d t
$$

Subject to:

$$
\begin{aligned}
& \frac{d C}{d t}=e_{C} \rho-\frac{C}{\tau} \\
& C(0)=C_{0} \\
& \alpha+\beta=1 \\
& 0 \leq u \leq 1
\end{aligned}
$$

Here $r$ is the continuous time discount rate. To solve this problem we set up the current value Hamiltonian with the transformed co-state variable $\psi$ and follow the regular steps:

$$
H(C, u, t)=C^{\alpha} e_{R}^{\beta}+\psi\left(e_{C} \rho-\frac{C}{\tau}\right)
$$

To find the optimal allocation policy, $u$, we solve the following equations:

$$
\begin{aligned}
& \frac{\partial H}{\partial u}=0 \\
& \frac{\partial H}{\partial C}=-\frac{d \psi}{d t}+r \psi \\
& \lim _{T \rightarrow \infty} e^{-r t} \lambda(T) \geq 0, \lim _{T \rightarrow \infty} e^{-r t} \psi(T) C(T)=0
\end{aligned}
$$

Solving the first constraint we find the following optimal allocation fraction which is similar to the finite horizon case:

$$
u_{\text {Dyn }}=\operatorname{Min}\left(1,\left(\frac{\beta}{\psi h \rho}\right)^{\frac{1}{1-\beta}} C\right)
$$

After replacing the optimum allocation in the second condition, the dynamics of co-state variable is described by the following equation:

$$
\frac{d \psi}{d t}=\psi\left(r+\frac{1}{\tau}\right)-(1-\beta)\left(\frac{\beta}{\psi h \rho}\right)^{\frac{\beta}{1-\beta}}
$$


In this case we observe that the equilibrium $\psi$ value satisfies the terminal conditions, and thus provides the following solutions for the optimal co-state trajectory and allocation:

$$
\begin{gathered}
\frac{d \psi}{d t}=0 \Rightarrow \psi=\left(\frac{\tau(1-\beta)}{(1+r \tau)\left(\frac{h \rho}{\beta}\right)^{\frac{\beta}{1-\beta}}}\right)^{1-\beta} \\
u=\operatorname{Min}\left(1, u^{*} \frac{C}{C^{*}}(1+r \tau)\right)
\end{gathered}
$$

In the infinite horizon discounted case the optimal allocation differs from the finite horizon, undiscounted, case with a factor of $(1+\mathrm{r} \tau)$ : if capabilities are slow to erode (large $\tau)$ and if discount rate is high, the baseline allocation favors revenue generation beyond the steady state optimal allocation. Moreover the infinite horizon case does not include the precipitous decline in the value of capability at the end of time horizon (because there is no end to the time horizon).

\section{S3- The effort allocation function and characteristic of the resulting phase diagram}

Variables and model definition (reproduced from the paper)

Revenue Function:

Allocated effort to revenue

Allocated effort to capability

System's dynamics

Optimal steady state allocation policy

Allocation heuristic used in this study

Target revenue

$$
\begin{aligned}
& R=C^{\alpha} e_{R}^{\beta}(1+S) \\
& e_{R}=u h \\
& e_{C}=(1-u) h \\
& \frac{d C}{d t}=e_{C} \rho-\frac{C}{\tau} \\
& u^{*}=\frac{\beta}{\alpha+\beta} \\
& u=\operatorname{Min}\left(1, u^{*}\left(\frac{R^{T}}{R_{u^{*}}}\right)^{\gamma}\left(\frac{C}{C^{*}}\right)^{1-\gamma \beta}\right) \\
& R^{T}=C^{* \alpha} e_{R}^{* \beta}
\end{aligned}
$$


Expected revenue using optimal steady state policy $R_{u^{*}}=C^{\alpha} e_{R}^{* \beta}(1+S)$

Effort to revenue under optimal steady state policy $\quad e_{R}^{*}=u^{*} h$

Capability using optimal steady state policy $\quad C^{*}=\left(1-u^{*}\right) h \rho \tau$

Throughout the rest of the document it is assumed that we are using a constant return to scale production function $(\alpha+\beta=1)$.

\section{Phase diagram}

The phase diagram for the system reflects the changes in capability $(\mathrm{dC} / \mathrm{dt})$ as a function of capability. Specifically, replacing the equation for allocation into the system's dynamics, we get:

$$
\frac{d C}{d t}=(1-u) h \rho-\frac{C}{\tau}=\left(1-\operatorname{Min}\left(1, u^{*}\left(\frac{R^{T}}{R_{u^{*}}}\right)^{\gamma}\left(\frac{C}{C^{*}}\right)^{1-\gamma \beta}\right)\right) h \rho-\frac{C}{\tau}
$$

after replacement and simplification, we get:

$$
\dot{C}=\frac{d C}{d t}=h \rho\left(1-\operatorname{Min}\left(1, u^{*}\left(\frac{C}{C^{*}}\right)^{1-\gamma} \frac{1}{(1+S)^{\gamma}}\right)\right)-\frac{C}{\tau}
$$

The allocation function thus has one adjustment factor that responds to the capability level, and another that responds to environmental shocks. The latter component reduces variability in response to the environmental shocks and the former either smoothes revenue $(\gamma>1)$ or fixes capability shortfalls $(\gamma<1)$ in response to deviations of capability. The response to capability level is thus the result of two competing forces, one which attempts to align the capability level with the optimal trajectory based on the optimal control policy, and another which compensates for falling capability by increasing allocation to revenue generation, thus smoothing the revenue trajectory. These forces are at balance when $\gamma=1$, capability renewal tendencies win for smaller $\gamma$ and revenue smoothing dominates for $\gamma \geq 1$.

For simplifying the analysis of the system, we focus on the deterministic version of the equation, where the impact of environmental noise is excluded from calculations of capability change.: 


$$
\dot{C}=h \rho\left(1-\operatorname{Min}\left(1, u^{*}\left(\frac{C}{C^{*}}\right)^{1-\gamma}\right)\right)-\frac{C}{\tau}
$$

By equating this equation to zero we find that it always has a fixed point at $C^{*}$ where capability equals the optimal steady state capability. The existence and number of other fixed points depends on $\gamma$.

1) $\gamma \leq 1$ :

For $0 \leq C \leq C^{*}$ we have:

$$
\dot{C}=h \rho\left(1-u^{*}\left(\frac{C}{C^{*}}\right)^{1-\gamma}\right)-\frac{C}{\tau} \geq h \rho\left(1-u^{*}\right)-\frac{C^{*}}{\tau}
$$

Yet the right hand side of inequality is by definition zero, so $\dot{C} \geq 0$.

Using a similar argument, it is easy to see that for $C \geq C^{*}$ the net rate of change in capability is always negative. Therefore for $\gamma \leq 1$ the phase diagram includes a single equilibrium at $C^{*}$ and no other fixed points, the system will always move back towards this equilibrium.

2) $\gamma>1$ :

Calling $C^{*}\left(\frac{1}{u^{*}}\right)^{\frac{1}{1-\gamma}}=C^{S}$, the net flow equation has two ranges:

$$
\begin{gathered}
\dot{C}=-\frac{C}{\tau} \text { if } C<C^{s} \\
\dot{C}=h \rho\left(1-u^{*}\left(\frac{C}{C^{*}}\right)^{1-\gamma}\right)-\frac{C}{\tau} \text { if } C \geq C^{s}
\end{gathered}
$$

Therefore at least one additional fixed point exists at $C=0$. We now focus on the behavior of $\dot{C}$ when $C \geq C^{s}$

First, we observe that $\dot{C}$ is a continuous function in $C$ that at $C^{s}$ takes the $-\frac{C}{\tau}$ value and at $C^{*}$ is zero. The extremum for $\dot{C}$ can be found by equating its derivative with respect to $\mathrm{C}$ to zero which provides the following unique solution: 


$$
\frac{\partial \dot{C}}{\partial C}=0 \Rightarrow C=\left((\gamma-1) h \rho \tau C^{* \gamma-1}\right)^{\frac{1}{\gamma}}
$$

On the other hand:

$$
\frac{\partial^{2} \dot{C}}{\partial C^{2}}=-(\gamma-1) \gamma r u^{*} C^{* \gamma-1} C^{-\gamma-1}
$$

All the terms in the equation are positive, except for the one negative sign, therefore the second derivative of capability flow with respect to capability is always negative in this region. As a result the extremum found above is the only maximum for the net capability flow function which should be above zero (given that $\dot{C}=0$ at $C^{*}$ ) and thus there is a single other point at which $\dot{C}=0$. This point can be found numerically ${ }^{8}$ by solving the rate-level equation for zero capability change rate. Given the positive first derivative of $\dot{C}$ with respect to $C$ at this point, it is also the only tipping point for the system.

To recap, when $\gamma \leq 1$, the system includes a single unique equilibrium at $C=C^{*}$. For $\gamma>1$ the system includes exactly three fixed points: two are stable equilibria at $C=0, C=C^{*}$ and one is a tipping point located in between.

\footnotetext{
${ }^{8}$ No general analytical solution exists for the location of tipping point.
} 